\title{
Cyclic performance of beam- column joints with extended column fixed at base. Part l: experimental investigation
}

Panuwat Joyklad

Graduate Student, School of Civil Engineering and Technology, Sirindhorn International Institute of Technology, Thammasat University, Pathumthani, Thailand

\section{Amorn Pimanmas}

Associate Professor, School of Civil Engineering and Technology, Sirindhorn International Institute of Technology, Thammasat University, Pathumthani, Thailand

Rajesh P. Dhakal

Associate Professor, Department of Civil and Natural Resources Engineering, University of Canterbury, Christchurch, New Zealand

The seismic performance of a non-seismically detailed reinforced concrete (RC) beam-column joint with column pinned and fixed at the base is experimentally investigated in this paper. Six half-scale RC beam-column specimens were tested to study the effect of inflection point on the cyclic behaviour of beam-column sub-assemblages. The specimens were separated into two groups. The shape of specimens in the first group was cruciform; the size of the column in those specimens was varied while the size of beam was kept nearly constant. The dimensions and reinforcing detail of specimens in the second group were identical to those in the first one except that the column was extended to the footing and fixed at the base. The main variable in this study was the relative stiffness between beam and column, which affects the position of the inflection point. The test results demonstrated a significant effect of inflection point position on the load capacity, joint shear stress and failure mode.

\section{Notation}

$A_{\mathrm{j}} \quad$ joint shear area $\left(\mathrm{mm}^{2}\right)$

$A_{\mathrm{s}} \quad$ area of beam tension reinforcement $\left(\mathrm{mm}^{2}\right)$

$A_{\mathrm{s}}^{\prime} \quad$ area of beam compression reinforcement $\left(\mathrm{mm}^{2}\right)$

a shear span of bottom column measured from the fixed base (mm)

$\boldsymbol{C}_{\mathrm{c}}^{\prime}, \boldsymbol{C}_{\mathrm{c}}$ compressive forces in concrete on opposite faces of beam-column joint $(\mathrm{kN})$

$\boldsymbol{C}_{\mathrm{s}}^{\prime}, \boldsymbol{C}_{\mathrm{s}}$ compressive forces in steel on opposite faces of beam-column joint $(\mathrm{kN})$

$c \quad$ the smaller of (a) the smallest distance measured from the surface of the concrete to the centre of a bar being developed and (b) one-half of the centre-to-centre spacing of the bars being developed

$d_{\mathrm{b}} \quad$ diameter of steel bar ( $\left.\mathrm{mm}\right)$

$f_{\mathrm{y}} \quad$ yield strength of steel bar (MPa)

$h_{1} \quad$ height of top column measured from centre of beam to point of applied load (mm)

$h_{2} \quad$ height of bottom column measured from centre of beam to fixed base $(\mathrm{mm})$

$h_{\mathrm{b}} \quad$ beam depth $(\mathrm{mm})$

$h_{\mathrm{c}} \quad$ column depth (mm)

$h_{\mathrm{t}} \quad$ height of column above the inflection point; $h_{\mathrm{t}}=\left(h_{1}+h_{2}\right)-a(\mathrm{~mm})$

$I_{\mathrm{b}} \quad$ moment of inertia of beam section $\left(\mathrm{mm}^{4}\right)$ moment of inertia of column section $\left(\mathrm{mm}^{4}\right)$ gross moment of inertia of beam section $\left(\mathrm{mm}^{4}\right)$ reinforcement index $1 \cdot 70,1.25$ and 1.00 for joints confined on all four faces, three faces or two opposite faces and others, respectively

beam span measured from centre of column to pinned support (mm)

beam span $(\mathrm{mm})$ column span (mm) bending moment at bottom section of bottom column $(\mathrm{kNm})$

bending moment at top section of bottom column (kNm) moment capacity of beam section $(\mathrm{kNm})$ beam reaction $(\mathrm{kN})$ bond anchorage capacity $(\mathrm{kN})$ tension force in top reinforcement $(\mathrm{kN})$ tension force in bottom reinforcement $(\mathrm{kN})$ bond stress $(\mathrm{MPa})$ beam shear force $(\mathrm{kN})$ column shear force $(\mathrm{kN})$ joint shear force $(\mathrm{kN})$ shear strength $(\mathrm{kN})$ joint shear strength (MPa) 
Cyclic performance of beam-column joints with extended column fixed at base. Part I: experimental investigation Joyklad, Pimanmas and Dhakal $v_{\text {ju }} \quad$ joint shear stress (MPa)

$\lambda \quad$ lightweight aggregate concrete factor (1.00 for normal concrete)

$\psi_{\mathrm{e}} \quad$ coating factor (1.00 for uncoated reinforcement)

$\psi_{\mathrm{s}} \quad$ bar size factor (0.80 for bar diameter less than No. 19)

$\psi_{\mathrm{t}} \quad$ bar location factor (1.00 for bottom reinforcing bar)

\section{Introduction}

The performance of reinforced concrete (RC) components under seismic excitation has always been a topic of much interest. Researchers have investigated the behaviour of beam-column joints and columns under reversed cyclic loads (e.g. Durrani and Wight, 1985; Ghee et al., 1989; Hanson and Conner, 1967; Jirsa, 1974; Paulay et al., 1978; Saatcioglu and Ozcebe, 1989; Soleimani et al., 1979; Uzumeri, 1977) and many of these previous works aimed to study seismically detailed connections designed according to modern seismic design codes. Studies focusing on underdesigned or substandard members are less common (Aycardi et al., 1994; Beres et al., 1992; Bing and Pan, 2007; Dhakal et al., 2005; Hakuto et al., 2000; Kuang and Wong, 2005; Kunnath et al., 1995; Linzhi et al., 2009; Park, 2002; Pessiki et al., 1990; Supaviriyakit et al., 2007). There are some salient characteristics of under-designed RC frames. For example, no or few lateral reinforcements are placed in the beam-column joint region, the amount of transverse reinforcement in the column is typically low and the column bar lap splices are normally placed immediately above floor level. These substandard reinforcing details are typical in most buildings in low- to moderateseismicity regions and in buildings in high-seismicity regions constructed before 1970 when modern seismic design practices were not prevalent.

Beam-column joints have been studied separately from columns. The specimens studied were typically cruciform shape as shown in Figure 1(a) (Benavent-Climent et al., 2010; Bing et al., 2009; Burnett and Trenberth, 1972; Quintero-Febres and Wight, 2001; Supaviriyakit and Pimanmas, 2008) with beams and columns extended from joint faces to the mid-length of members where inflection points are assumed to occur. For columns, singlecurvature (i.e. cantilever) (Figure 1(b)) and double-curvature (Figure 1(c)) test set-ups are two commonly reported schemes (Vintzileou and Stathatos, 2007). Strictly speaking, a cruciformshaped beam-column joint specimen with all ends pinned cannot represent the first floor of a building frame where the column is supported by footing at the base since the inflection point is not

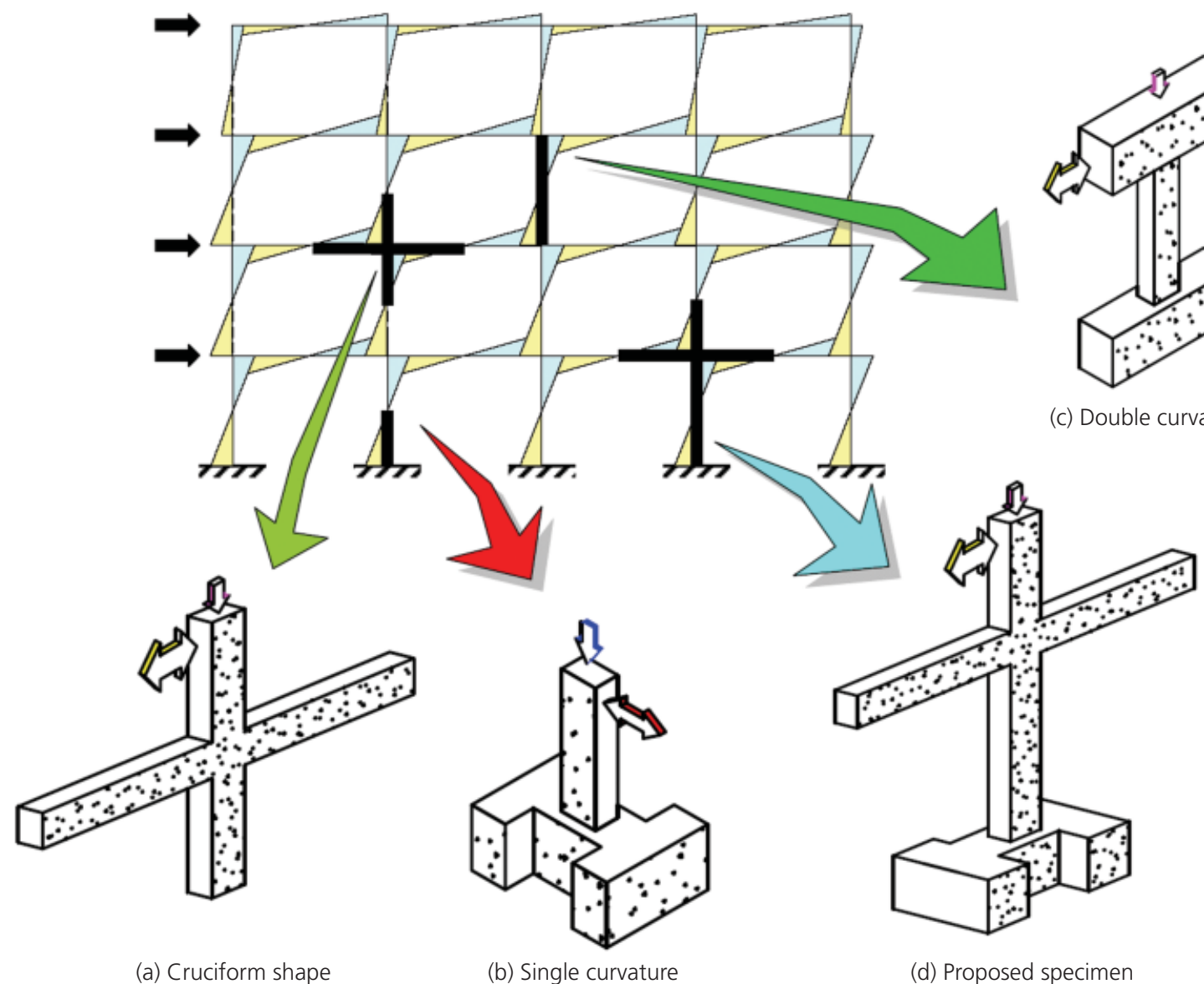

Figure 1. Test specimens of structural members 
necessarily located at the column mid-height as is assumed in the cruciform or double-curvature set-up. Furthermore, a column is not a cantilever, as in the single-curvature test set-up. Application of these test results to the ground floor of actual RC building frames may thus lead to an erroneous interpretation of its performance.

Unless the beam-column joint and the column are integrated in the test set-up, separate studies may fail to capture their mutual interaction. The location of the inflection point in the column, which is governed by the relative beam and column stiffness, has an important role to play. Modern seismic design methods pay attention to the relative strength between beam and column sections to ensure a weak beam-strong column mechanism, and the beam and column stiffnesses are only addressed in terms of limiting lateral drift (ICC, 2006). However, the effect of relative stiffness on the location of the inflection point and the consequent failure mode is not normally considered in design.

The significant influence of the relative beam and column stiffness are schematically illustrated in Figure 2, which shows the bending moment diagram for three building frames subjected to lateral load, in which the column depth was $0.5,1.0$ and 2.0 times the beam depth while the width was kept the same. The figure shows that the inflection point is located near the midheight of the column for a small column size and gradually moves towards the beam-column joint zone as the column depth increases. In order to capture variation of the inflection point position and its consequent effect on the seismic behaviour of a ground-floor RC frame, it is important to study the joint-column sub-assemblage as shown in Figure 1(d). Very few previous studies (Chiba et al., 1992; Sugano and Nagashima, 1985) have reported tests on these types of sub-assemblage.

This paper presents an experimental programme on six half-scale specimens that separate and combine RC joints and columns under reversed cyclic loads. The specimens represent typical lowto mid-rise $\mathrm{RC}$ frames designed for gravity load only. The
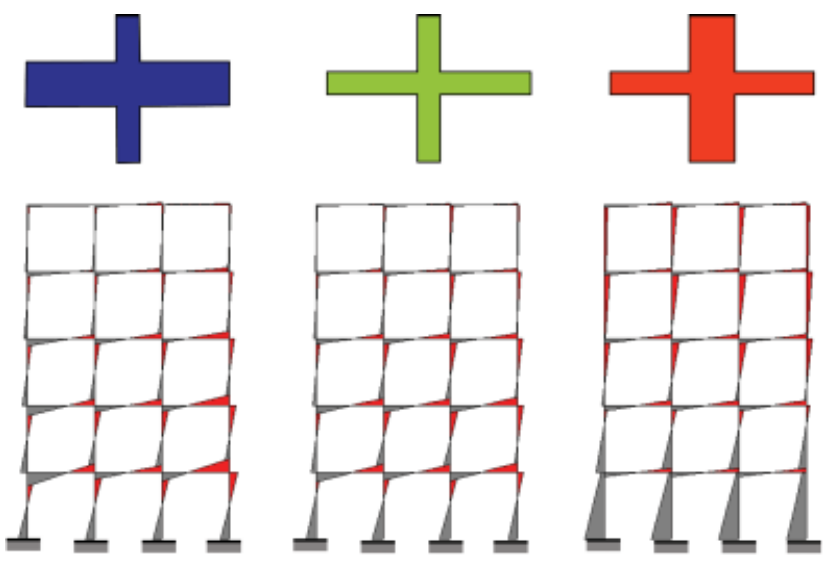

Figure 2. Bending moment diagram for building with different member sizes interaction between the beam-column joint and the column is explored based on the relative beam and column stiffness and the location of the inflection point in different specimens.

\section{Experimental programme}

The experimental programme studied six half-scale specimens divided into two series. The study parameter is the location of the inflection point, which is governed by the relative column to beam stiffness. The three specimens in the first series were a cruciform-shaped beam-column joint with the beam and column extended from joint faces to the member mid-length, where the inflection point is traditionally assumed to occur. These three specimens are denoted JL, JM and JS. The beam depth was $300 \mathrm{~mm}$ in all three specimens but the column depth in the loading direction was varied: $400 \mathrm{~mm}$ (JL); $350 \mathrm{~mm}$ (JM); $300 \mathrm{~mm}$ (JS). Based on the sizes of the beam and column, the relative column to beam stiffness

$$
\frac{\sum\left(I_{\mathrm{c}} / L_{\mathrm{c}}\right)}{\sum\left(I_{\mathrm{b}} / L_{\mathrm{b}}\right)}
$$

was calculated to be 5.99 (JL), 3.06 (JM) and 1.93 (JS). The reinforcement details and cross-sections of beam and column in these specimens are shown in Figures 3 and 4.

The three specimens comprising the second series (denoted CJL, CJM and CJS) had cross-section and reinforcement details identical to their companion specimens in the first series except that the bottom column was extended and fixed at the base. These specimens were supposed to represent part of the building frame from the base to the mid-height of the second storey (Figure 1(d)) (i.e. fully including the first floor of the building). Deformed bars of $12 \mathrm{~mm}$ diameter were used as longitudinal reinforcement in the beam and column whereas $3 \mathrm{~mm}$ diameter round bars were used for stirrups and ties. Table 1 shows the average tested yield and tensile strengths of these bars. The average tested cylindrical compressive strength of concrete at the day of testing is given in Table 2. The properties of all tested specimens are summarised in Table 3.

The test set-up and boundary conditions are shown in Figure 5. Lateral displacement was applied at the top of the column through a $500 \mathrm{kN}$ hydraulic actuator. The ends of the beam were supported by rollers that allowed free horizontal movement to simulate lateral drift. An axial load, equal to $12 \cdot 5 \%$ of the column axial capacity, was applied to the column by means of vertical prestressing. The column was pushed forward and pulled backward in a reversed cyclic pattern with target lateral drifts of $0 \cdot 25 \%, 0 \cdot 50 \%, 0 \cdot 75 \% \ldots$ as shown in Figure 6 . The target loop was repeated twice for each drift level. The displacement cycles were continued beyond the peak load to trace the post-peak behaviour. The test was stopped when the applied load dropped to less than $80 \%$ of the maximum load (CEB, 1996). 


\section{Frame \\ Sub-assemblages \\ (Second series)}

4 PC strands $15.2 \mathrm{~mm}$ for $\mathrm{CJ}$

2 PC strands $15.2 \mathrm{~mm}$ for CJM \& CJS -

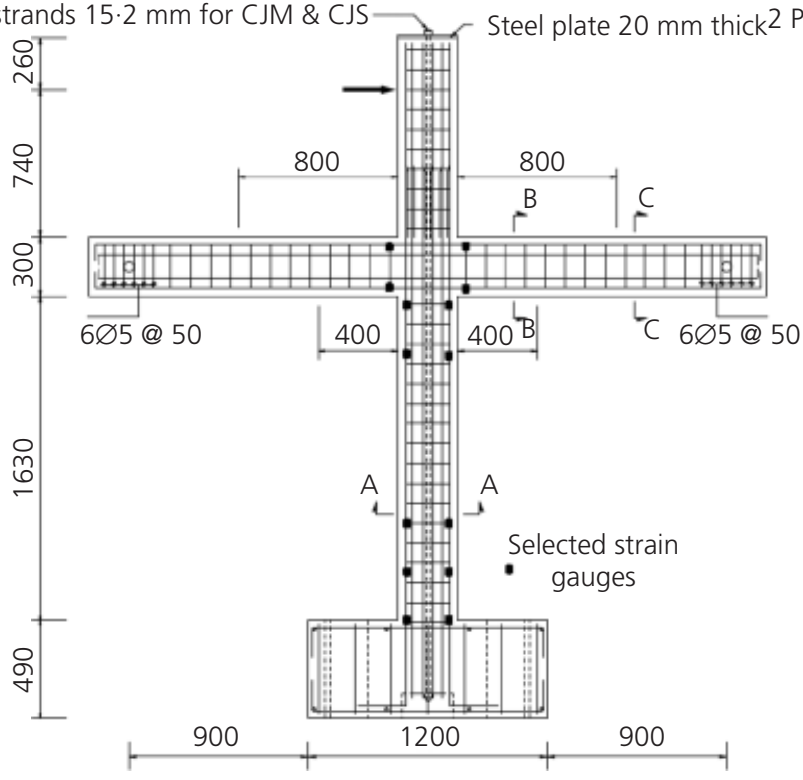

Beam-column

connection

(First series)

4 PC strands $15.2 \mathrm{~mm}$ for $\mathrm{JL}$

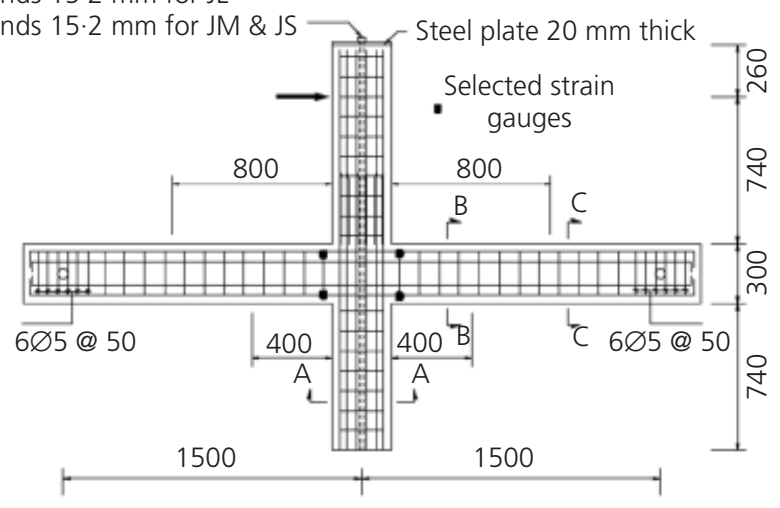

Figure 3. Geometry, dimensions and reinforcement of all

specimens (dimensions in $\mathrm{mm}$ )

Section A-A

Figure 4. Cross-section of beams and columns (dimensions in $\mathrm{mm}$ ) 


\begin{tabular}{lcc}
\hline & \multicolumn{2}{c}{ Strength: MPa } \\
\cline { 2 - 3 } & Series 1 & Series 2 \\
\hline Yield strength: DB12 & 479.32 & 494.99 \\
Tensile strength: DB12 & 606.06 & 609.03 \\
Yield strength: $\varnothing 3 \mathrm{~mm}$ & 306.07 & $518 \cdot 14$ \\
Tensile strength: $\varnothing 3 \mathrm{~mm}$ & 387.50 & $592 \cdot 14$ \\
Table 1. Summary of steel strengths & & \\
\hline
\end{tabular}

\begin{tabular}{lcccccc}
\hline & \multicolumn{6}{c}{ Cylinder concrete strength: MPa } \\
\cline { 2 - 7 } & JL & JM & JS & CJL & CJM & CJS \\
\hline Bottom column & 22.56 & 22.76 & 24.24 & 26.40 & $28 \cdot 16$ & 24.78 \\
Beams and joint & 23.02 & 26.29 & 25.95 & 24.61 & 26.06 & 24.19 \\
Top column & 22.43 & 23.20 & 23.13 & 23.86 & 23.36 & 23.75
\end{tabular}

Table 2. Summary of cylinder concrete strengths

\begin{tabular}{|c|c|c|c|c|c|c|}
\hline & \multicolumn{3}{|c|}{ Series 1} & \multicolumn{3}{|c|}{ Series 2} \\
\hline & $J \mathrm{~L}$ & $\mathrm{JM}$ & JS & CJL & CJM & CJS \\
\hline Support conditions & Pinned & Pinned & Pinned & Fixed & Fixed & Fixed \\
\hline Column depth: mm & 400 & 350 & 300 & 400 & 350 & 300 \\
\hline Column width: mm & 300 & 200 & 200 & 300 & 200 & 200 \\
\hline Beam depth: mm & 300 & 300 & 300 & 300 & 300 & 300 \\
\hline Beam width: mm & 200 & 175 & 175 & 200 & 175 & 175 \\
\hline Column reinforcement ratio: \% & $2 \cdot 45$ & $2 \cdot 91$ & 4.52 & $2 \cdot 45$ & $2 \cdot 91$ & 4.52 \\
\hline Beam bottom reinforcement ratio: \% & 0.84 & 0.96 & $1 \cdot 44$ & 0.84 & 0.96 & $1 \cdot 44$ \\
\hline Beam top reinforcement ratio: \% & $1 \cdot 26$ & $1 \cdot 44$ & 1.91 & $1 \cdot 26$ & 1.44 & 1.91 \\
\hline Transverse reinforcement ratio in column: \% & $0 \cdot 188$ & $0 \cdot 212$ & $0 \cdot 212$ & $0 \cdot 188$ & $0 \cdot 212$ & $0 \cdot 212$ \\
\hline Transverse reinforcement ratio in beam: \% & $0 \cdot 212$ & $0 \cdot 242$ & $0 \cdot 242$ & $0 \cdot 212$ & $0 \cdot 242$ & $0 \cdot 242$ \\
\hline Axial load ratio & $0 \cdot 217$ & $0 \cdot 185$ & $0 \cdot 202$ & $0 \cdot 230$ & $0 \cdot 169$ & $0 \cdot 186$ \\
\hline
\end{tabular}

Table 3. Properties of tested specimens

Various instruments were attached to the specimens. The horizontally applied force was measured by a load cell. Deformation of members (such as horizontal displacement at the top of column, flexural rotations in beams and column, shear deformation in beams, column and joint, and rocking angle at the interface between joint face and beams and column base) was measured using linear variable displacement transducers (LVDTs). The strains in reinforcements at critical locations (shown as black dots in Figure 3) were monitored by electric resistance strain gauges. in the beam, column and beam-column joint. As for the beamcolumn joint, the horizontal joint shear force and anchorage bond force are commonly referred to in design codes (ACI, 2008; SANZ, 2006). As shown in Figure 7, when a beam-column joint is acted on by a lateral load, the joint is subjected to a horizontal joint shear force. To satisfy equilibrium, the horizontal joint shear force has to be balanced by the horizontal component of the diagonal strut. An equation for the horizontal joint shear force can be derived using equilibrium of horizontal forces

\section{Test results and discussion}

The test results are discussed in terms of observed damage, failure mode, load-deflection hysteretic response and forces distributed
1. $\boldsymbol{V}_{\mathrm{ju}}=\boldsymbol{T}+\boldsymbol{T}^{\prime}-\boldsymbol{V}_{\mathrm{c}}$ 
Cyclic performance of beam-column joints with extended column fixed at base. Part I: experimental investigation Joyklad, Pimanmas and Dhakal

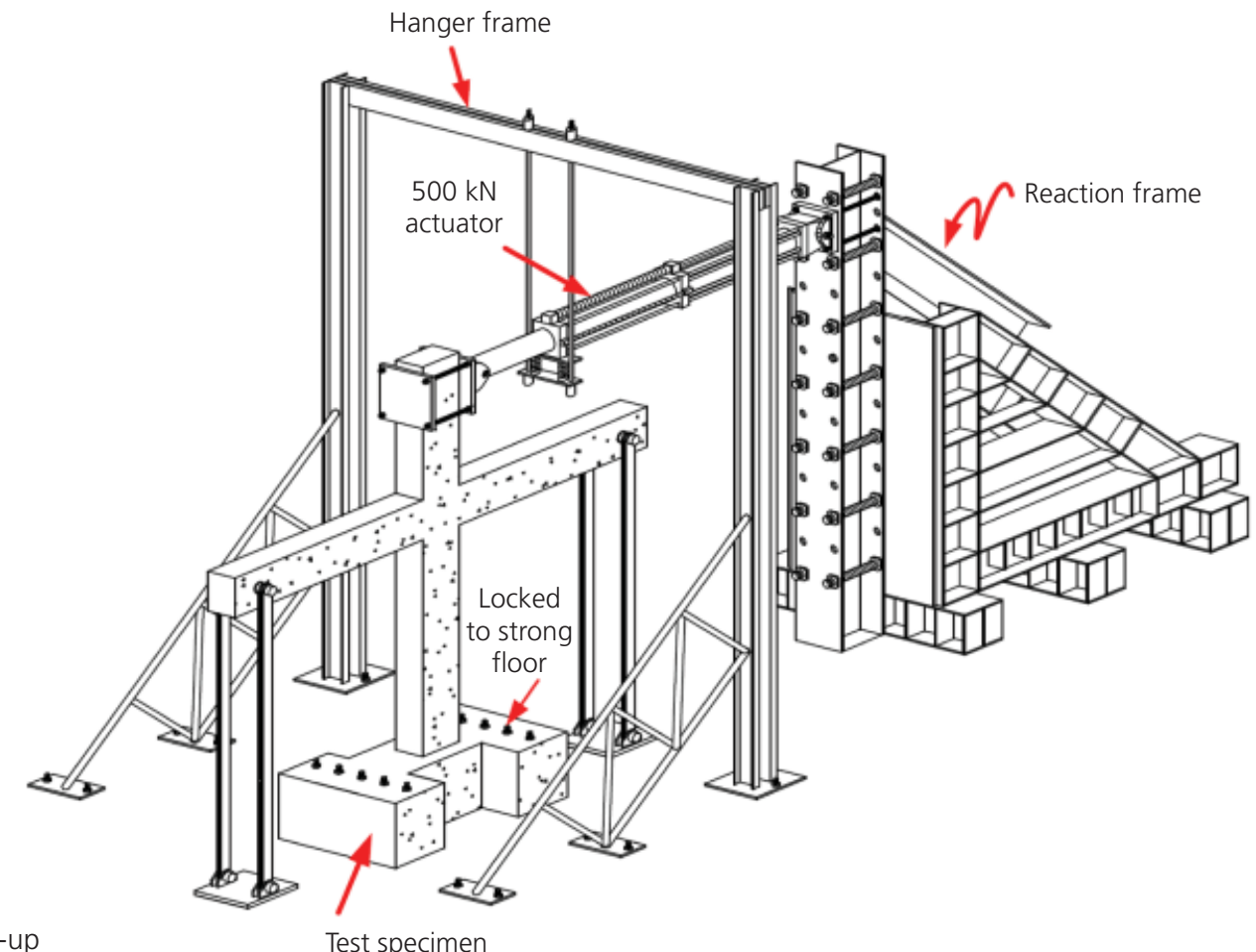

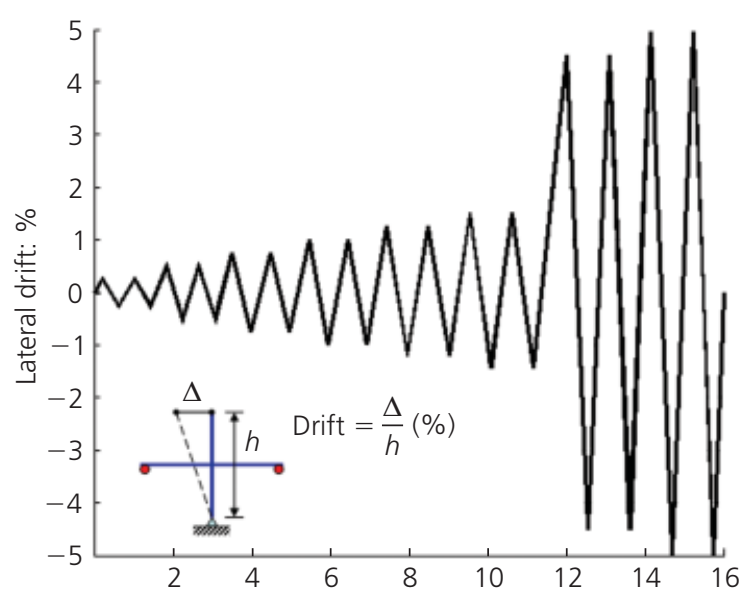

(a)

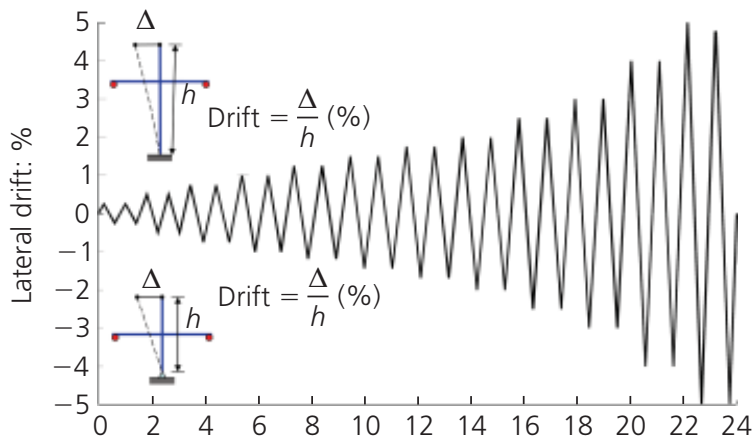

(b)

Figure 6. Displacement history: (a) specimen JL; (b) all specimens

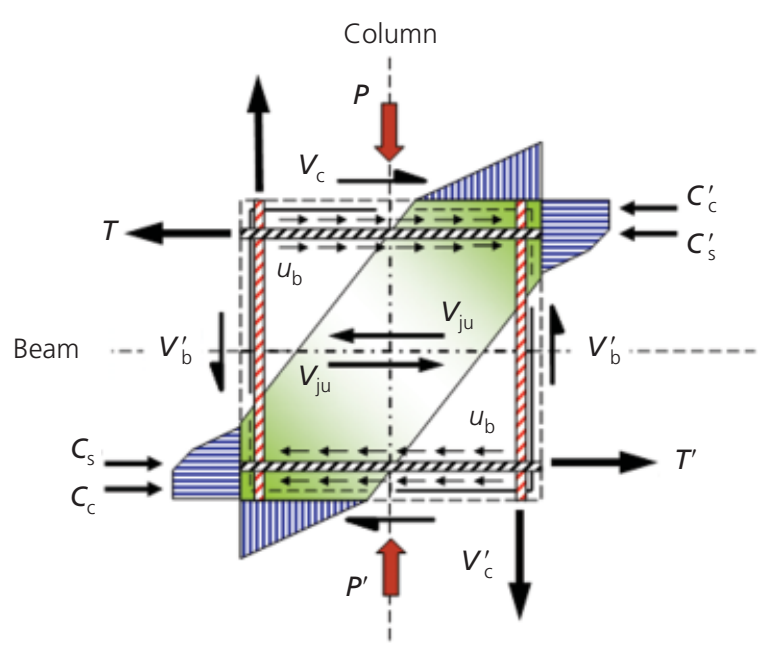

Figure 7. Forces in the beam-column joint

where $\boldsymbol{T}$ is the tensile force carried by the reinforcement in one column face, $\boldsymbol{T}^{\prime}$ is the tensile force at the opposite column face and $\boldsymbol{V}_{\mathrm{c}}$ is the column shear force transferred through the joint. If the joint shear force is greater than the joint shear capacity $\boldsymbol{V}_{\mathrm{n}}$, joint shear failure occurs. ACI 318 (ACI, 2008) provides the formula for joint shear capacity as

2. $\quad V_{\mathrm{n}}=k\left(f_{\mathrm{c}}^{\prime}\right)^{1 / 2} A_{\mathrm{j}}$ 
Magazine of Concrete Research

Volume 64 Issue 9
Cyclic performance of beam-column joints with extended column fixed at base. Part I: experimental investigation Joyklad, Pimanmas and Dhakal where $k$ is $1.70,1.25$ and 1.00 for joints confined on all four faces, three faces or two opposite faces and others, respectively. On the other hand, standard NZS 3101 (SANZ, 2006) limits the joint shear stress (calculated as the joint shear force divided by the joint area) to below $0 \cdot 2 f_{\mathrm{c}}^{\prime}$ to avoid joint shear failure.

The average bond stress of beam bars passing through a joint can be calculated from

$$
\text { 3. } u_{\mathrm{b}}=\frac{\left(f_{\mathrm{s}}-f_{\mathrm{s}}^{\prime}\right) d_{\mathrm{b}}}{4 h_{\mathrm{c}}}
$$

where $f_{\mathrm{s}}$ and $f_{\mathrm{s}}^{\prime}$ are stresses in longitudinal bars on opposite column faces, $d_{\mathrm{b}}$ is the bar diameter and $h_{\mathrm{c}}$ is the column depth.

\section{Crack pattern and observed damage}

The crack patterns observed in various components of the tested specimens are reported: photographs of the specimens after testing are illustrated in Figure 8 and the damage zones of specimens in the second series are shown in Figure 9.

\section{Specimen JL}

The first flexural crack occurred in the beam during $0-0 \cdot 25 \%$ drift cycles, and then grew in size and number in later cycles. The first diagonal crack occurred in the joint panel at $1.25 \%$ drift. At $4.5 \%$ drift, concrete in the compression zone of the beam crushed and spalled off, thereby exposing beam bars as shown in Figure 8(a). On the contrary, damage in the joint panel was slight. The specimen failed in flexural mode in the beam. It is noted that even though the specimen lacked ductile reinforcement details and was not designed to sustain seismic force, it performed fairly well. This good performance can probably be attributed to the relatively large size of the column. As a result, both the horizontal joint shear stress and the bond stress of beam longitudinal bars were small. Moreover, as the column is relatively stronger than the beam, the specimen behaved according to the strong column-weak beam principle.

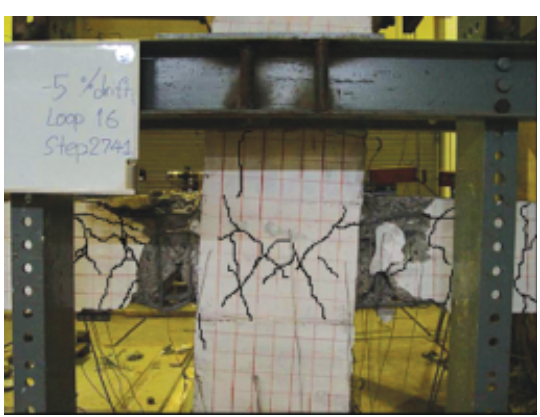

(a)

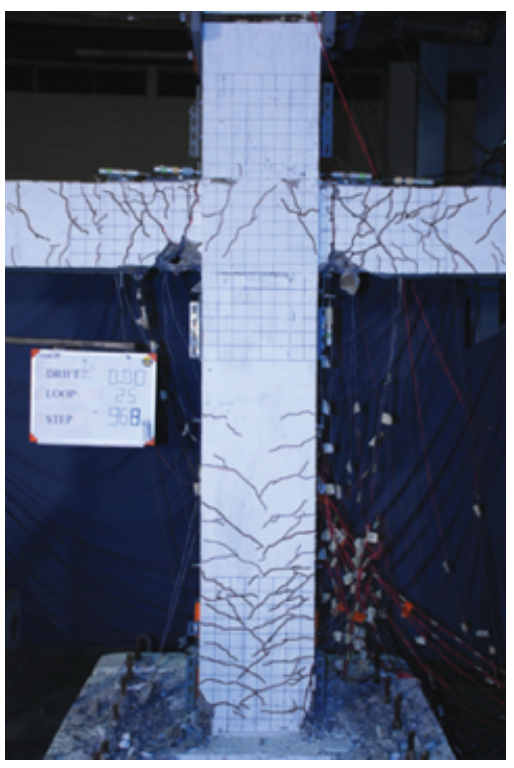

(d)

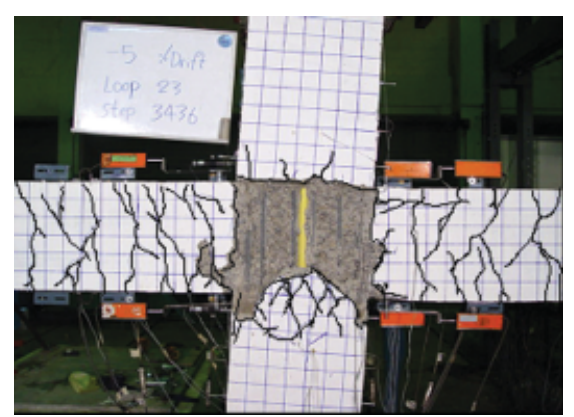

(b)

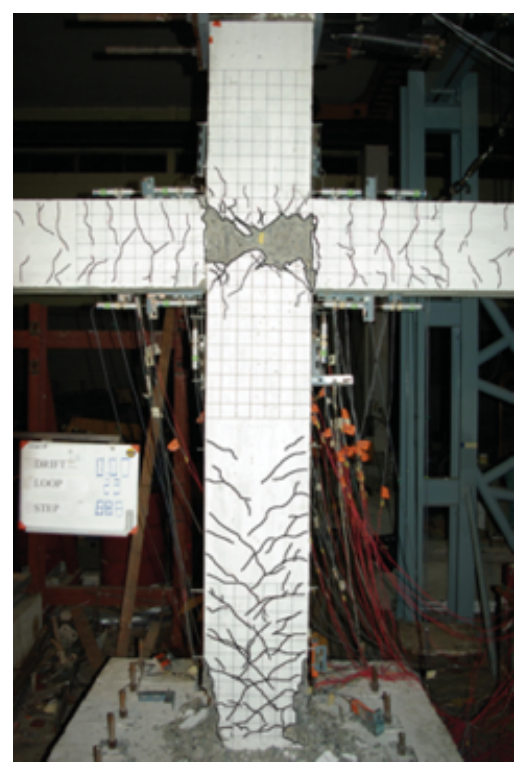

(e)

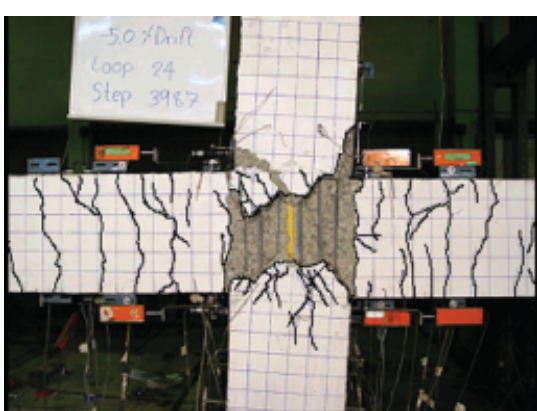

(c)

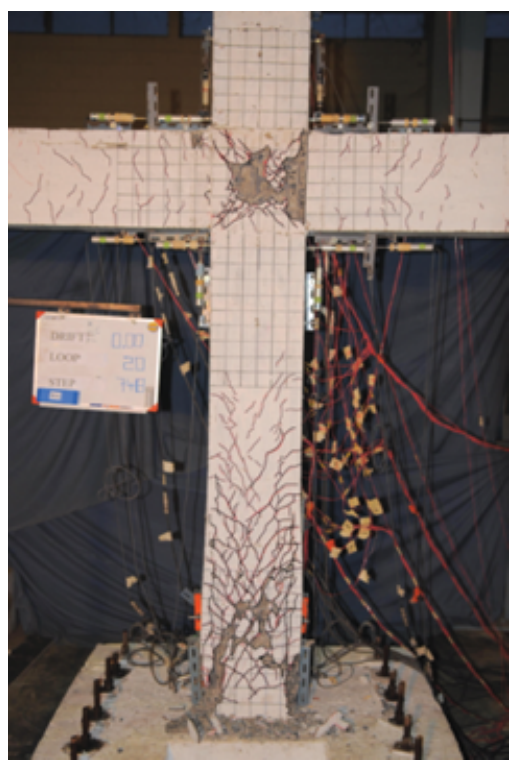

(f)

Figure 8. Crack patterns observed in the tested specimens 
Cyclic performance of beam-column joints with extended column fixed at base. Part I: experimental investigation Joyklad, Pimanmas and Dhakal

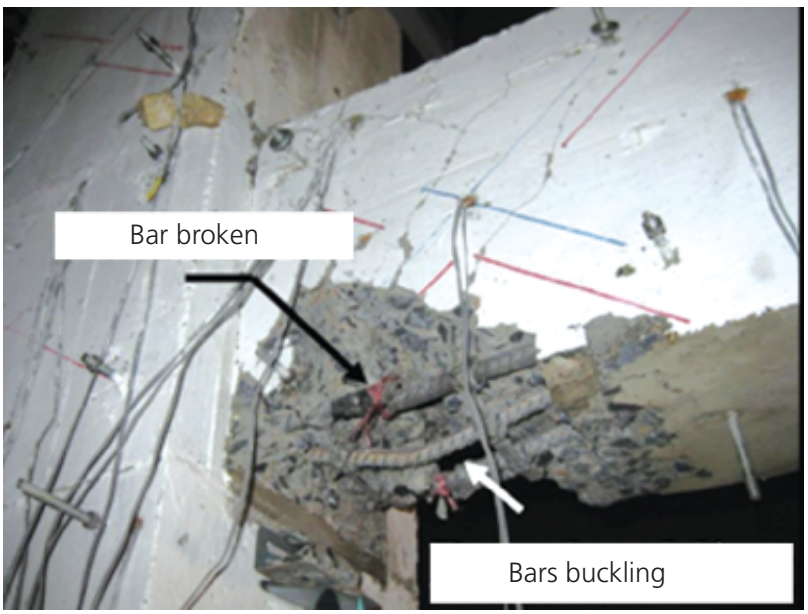

(a)

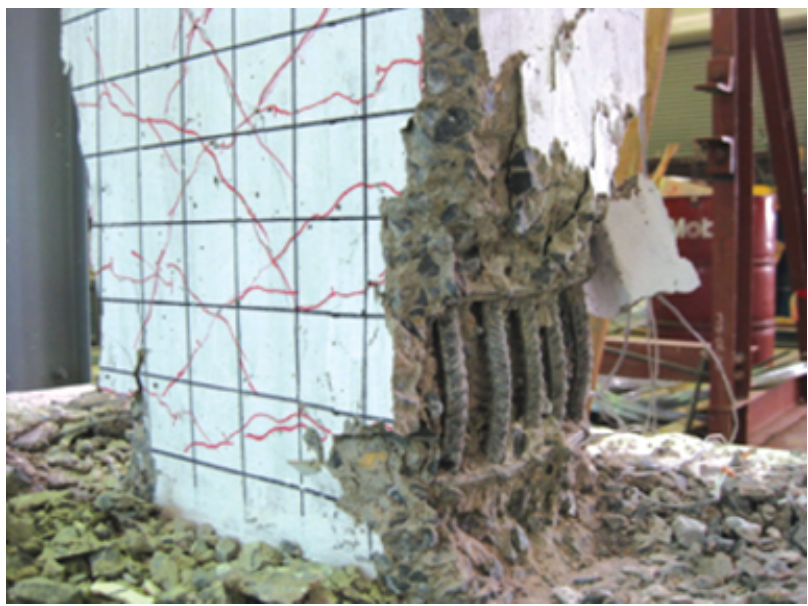

(b)

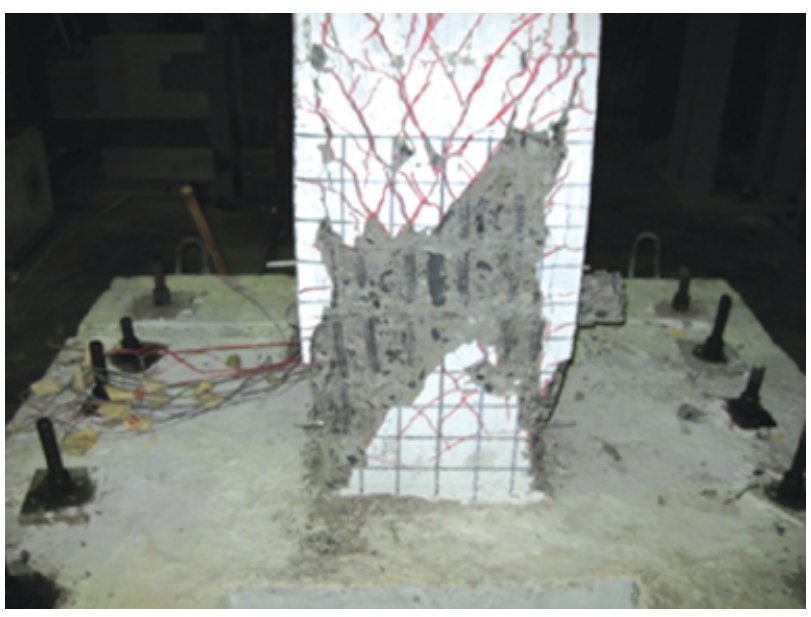

(c)

Figure 9. Local damage in specimens in series 2 specimens

\section{Specimens JM and JS}

The behaviours of JM and JS were quite similar. Flexural cracks occurred in the beam during $0-0 \cdot 25 \%$ drift cycles. The first diagonal crack occurred in the joint panel at $0 \cdot 5 \%$ drift. Flexural cracks in the beam and diagonal cracks in the joint panel grew in size and number until the specimen reached peak load at $1.75 \%$ drift for specimen JM and $1.5 \%$ drift for specimen JS. After this cycle, no new cracks formed in the beam, but diagonal cracks continued to widen in the joint panel, followed by spalling of concrete at the centre of the joint area. At $3 \%$ drift, the concrete spalled off over a wider area of the joint panel and exposed the column longitudinal bars. The test was continued until 5\% drift when spalling covered the entire joint area (Figures $8(\mathrm{~b})$ and 8(c)). It can be seen that both specimens (JM and JS) failed by joint shear failure.

\section{Specimen CJL}

The first flexural crack occurred in the beam at $0 \cdot 25 \%$ drift. At $0.5 \%$ drift, the first flexural crack occurred at the base of the column and some inclined cracks were found in the joint panel. In later cycles, more flexural cracks occurred in both beam and column. At $3 \%$ drift, concrete in the beam compression zone crushed and spalled off. After 3.5\% drift, beam bars buckled and the specimen rapidly lost its strength (Figure $8(\mathrm{~d})$ ). At $4 \%$ drift, the bottom longitudinal bars in the beam fractured (Figure 9(a)). It is noted that the failure mode of CJL was similar to that of specimen JL.

\section{Specimen CJM}

Flexural cracks appeared in both beam and column at $0.5 \%$ drift. Diagonal cracks appeared in the joint panel at $0.75 \%$ drift and widened considerably in later cycles. Concrete in the joint panel started to spall off at $2.5 \%$ drift. Flexural cracks at the column base continued to grow until concrete at the base of the column crushed at $2.5 \%$ drift. As the drift ratio increased, damage was concentrated in the compression zone at the column base (Figure 9(b)). Loading was terminated at $4 \%$ drift. Failure of specimen CJM was caused by crushing of concrete at the column base together with excessive shear cracks in the joint panel (Figure 8(e)).

\section{Specimen CJS}

The behaviour of specimen CJS was similar to that of CJM during the $0 \cdot 25-0 \cdot 75 \%$ drift cycles except that flexural cracks in the column were extended into flexural-shear cracks at $0.75 \%$ drift. Very few flexural cracks appeared in the beam while several diagonal cracks emerged in the joint panel. At $1 \%$ drift, inclined flexural cracks in the column started to extend from the tension side to the compression side. Between $1 \cdot 25 \%$ and $2 \%$ drift cycles, concrete in the beam-column joint spalled off while the inclined cracks in the column extended and widened. Specimen CJS failed at $3 \%$ drift by a combination of shear failure in the bottom column and joint region (Figures 8(f) and 9(c)). It should be noted that longitudinal reinforcement did not yield anywhere in the specimen.

\section{Hysteresis response}

\section{Specimens JL, JM and JS}

The hysteresis loop of specimen JL is shown in Figure 10(a). Elastic behaviour can be seen during $0-0 \cdot 25 \%$ drift. The beam 
Cyclic performance of beam-column joints with extended column fixed at base. Part I: experimental investigation Joyklad, Pimanmas and Dhakal

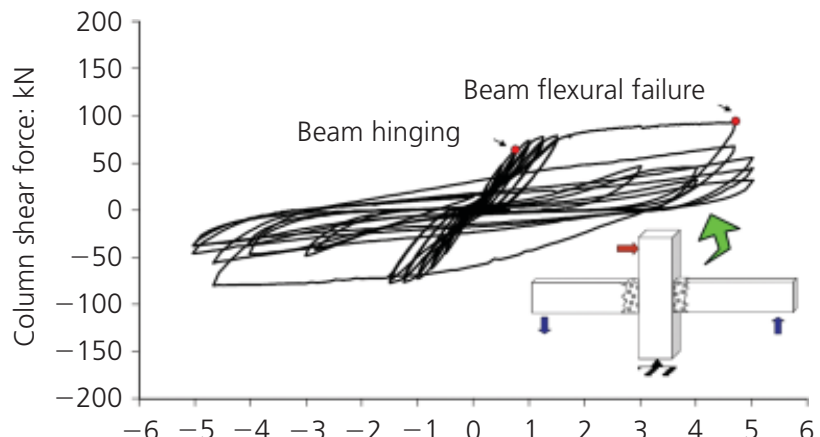

(a) JL

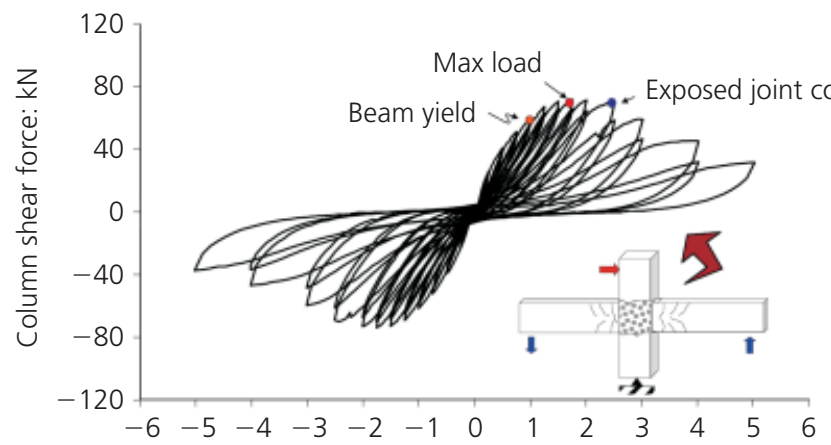

(b) JM

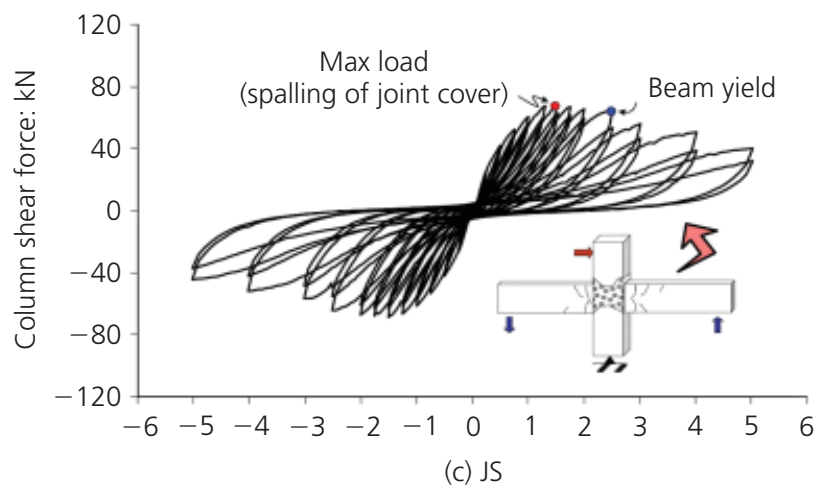

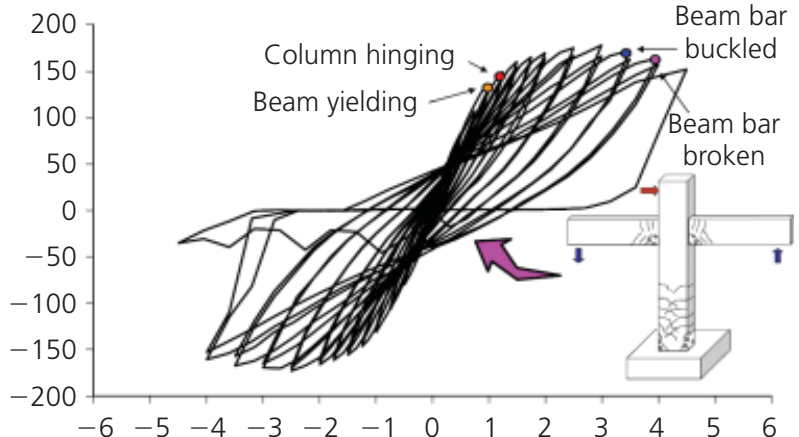

(d) CJL

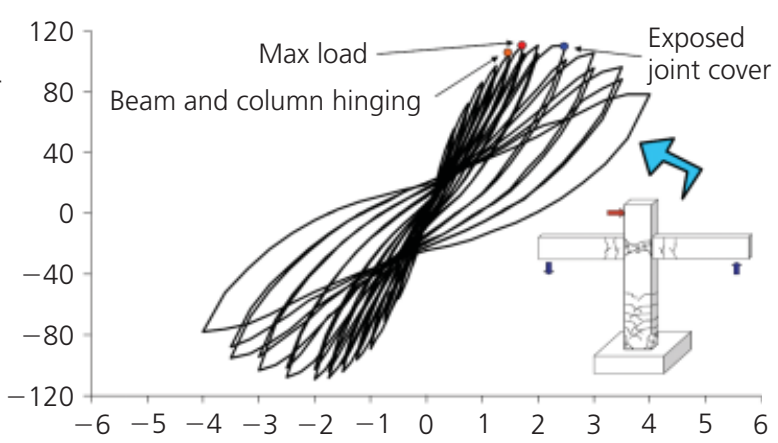

(e) CJM

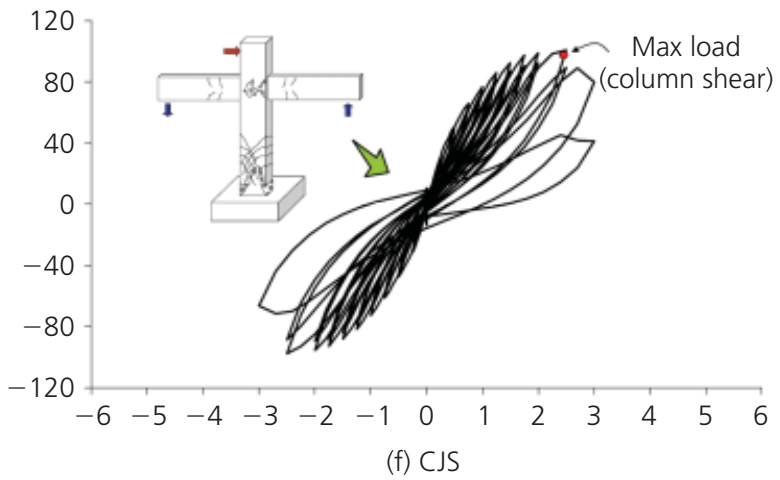

Figure 10. Force-drift ratio relationship

yielded at $1 \%$ drift, followed by a slight increase in column shear force. The yield load was maintained until $4.5 \%$ drift when the specimen reached the maximum column shear force of $91.9 \mathrm{kN}$. The hysteresis loops are large, indicating good energy dissipation.

The load-deflection response of specimens JM and JS is shown in Figures 10(b) and 10(c) respectively. The yielding of main reinforcements in the beam occurred at $1 \%$ and $2.5 \%$ drift for specimens JM and JS respectively. The maximum column shear force was $71.8 \mathrm{kN}$ at $1.75 \%$ drift for specimen JM and $68.1 \mathrm{kN}$ at $1.5 \%$ drift for specimen JS. Both specimens failed by joint shear failure. It can be seen that JM reached yielding before joint failure, while JS was subjected to joint failure before beam bar yielding. In both cases, however, the hysteresis loops were quite pinched due to bond deterioration and concentrated damage in the joint region.

\section{Specimens CJL, CJM and CJS}

The load-deflection response of specimen CJL is shown in Figure 10(d). Beam reinforcements started to yield at $1 \%$ drift, followed by yielding of column bars at $1.25 \%$ drift. The yield load increased until it reached the maximum force of $177.8 \mathrm{kN}$ at $3 \%$ drift ratio. As can be seen, the hysteresis loops are wide, showing high energy dissipation. The sudden drop in column shear force is due to buckling and fracture of beam bars at $3.5 \%$ and $4 \%$ drift respectively.

Figure 10(e) shows the load-deflection response of specimen CJM. The column shear force reached the maximum load of $110.2 \mathrm{kN}$ at $2.5 \%$ drift. Yielding of longitudinal reinforcements in the beam and column occurred at $1.5 \%$ drift. After reaching the peak load, the column shear force dropped rapidly. Compared with its companion specimen JM (Figure 10(b)), the hysteresis 
loop of CJM was larger, indicating higher energy dissipation. This indicates that the behaviour is controlled by yielding in the column rather than by shear failure in the beam-column joint.

The load-deflection response of CJS is shown in Figure 10(f). The longitudinal reinforcements in both beam and column did not yield. The maximum column shear force was $100.8 \mathrm{kN}$ at $2.5 \%$ drift. At maximum column shear force, the load dropped suddenly due to the abrupt column shear failure. The hysteresis loop was also pinched.

\section{Envelope column shear force and normalised joint shear force}

The envelope of column shear force for each pair of tested specimens is shown in Figure 11. A significant difference can be seen between specimens in both series. Specimens CJL, CJM and CJS attained considerably higher strength than their companion specimens. To be more specific, column shear forces in specimens CJL, CJM and CJS were $93.44 \%, 56.54 \%$ and $48 \%$ larger than those of JL, JM and JS respectively. The difference in the maximum force is attributed to the location of the inflection point. As shown in Figure 12, force equilibrium of the subassemblage requires that

4. $\quad V_{\mathrm{c}} h_{\mathrm{t}}=\boldsymbol{V}_{\mathrm{b}}(2 L)$

\section{5. $\quad \boldsymbol{V}_{\mathrm{b}} L=\boldsymbol{M}_{\mathrm{nb}}$}

Using Equation 5, $\boldsymbol{V}_{\mathrm{b}}$ can be determined from the moment capacity of the beam section $\boldsymbol{M}_{\mathrm{nb}}$ and then $\boldsymbol{V}_{\mathrm{c}}$ can be computed using Equation 4. The nominal beam moment capacities are approximately 64, 63 and $77 \mathrm{kNm}$ for specimens $\mathrm{L}, \mathrm{M}$ and $\mathrm{S}$ respectively. For specimen $\mathrm{JL}, h_{\mathrm{t}}$ is predetermined to be $h_{1}+0.5 h_{2}$ while $h_{\mathrm{t}}$ is less in CJL because the inflection point is located significantly higher than the mid-point of the lower column. Hence, as per Equation $4, \boldsymbol{V}_{\mathrm{c}}$ in specimen CJL must be larger than that in JL. Concurrently, because the shear force in the column is higher, the column becomes more vulnerable to bending and/or shear failure in CJL. This explanation agrees well with the observation that specimens CJM and CJS are subjected, respectively, to bending failure and shear failure at the column base in addition to the joint shear failure, which is the failure mode of specimens JM and JS.

The horizontal joint shear force transmitted in the joint panel can be calculated using Equation 1. In the experiment, tension forces $\boldsymbol{T}$ and $\boldsymbol{T}^{\prime}$ were obtained from strains of steel bars measured at opposite column faces (Figure 13). The measured strains were converted to stresses via the Ramberg-Osgood cyclic stressstrain law (Ramberg and Osgood, 1943). The normalised horizontal joint shear force was then calculated by dividing the horizontal joint shear force by the joint area. Figure 14 shows a comparison

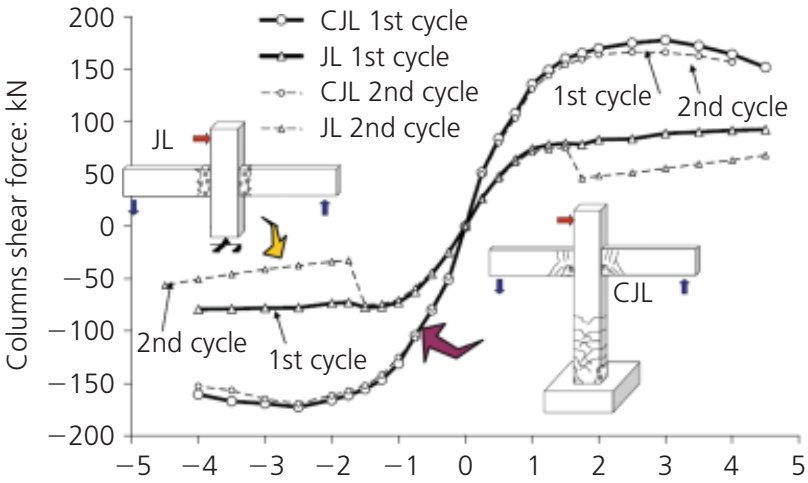

(a) L specimens

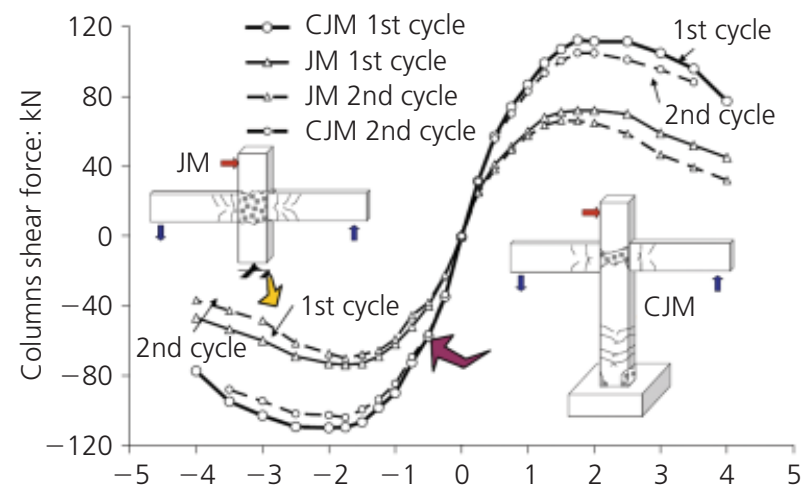

(b) M specimens

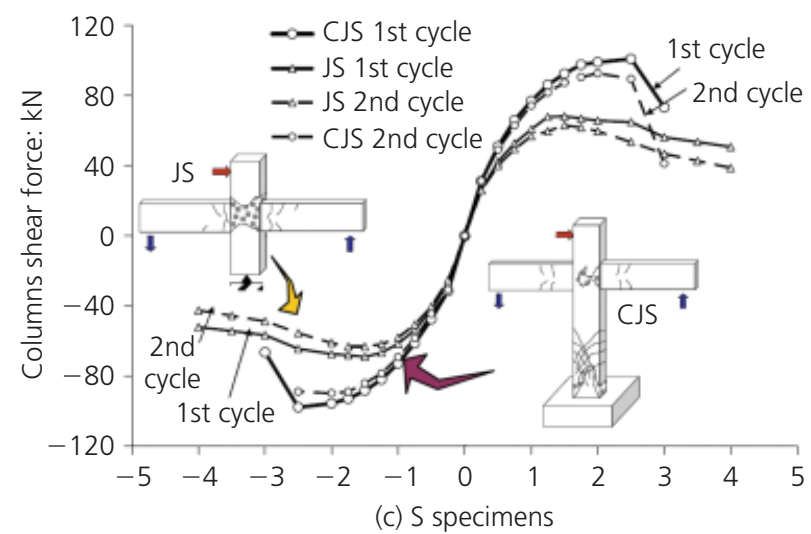

Figure 11. Comparison of envelope column shear force

of normalised horizontal joint shear forces in the specimens of the two series. As can be seen, while the column shear force in $\mathrm{C}$ specimens is larger, the normalised horizontal joint shear force is lower. The lower value of normalised horizontal joint shear force is due to the larger value of column shear force $\left(\boldsymbol{V}_{\mathrm{c}}\right)$ which is subtracted in Equation 1. As the normalised horizontal joint shear force is lower in specimens CJM and CJS, the joint is subjected to less damage than specimens JM and JS respectively. In Figure 14 , the joint shear strength calculated according to ACI 318 (ACI, 2008) is also shown for comparison. It can be seen that the normalised horizontal joint shear stress of $\mathrm{M}$ and $\mathrm{S}$ specimens exceeded the joint shear strength while the $\mathrm{L}$ specimens showed 


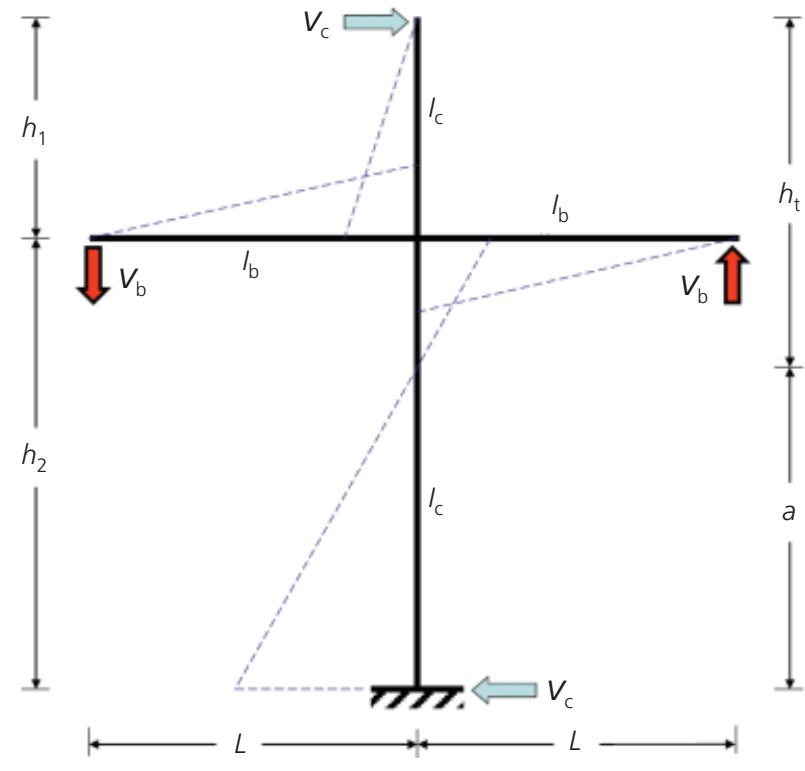

Figure 12. Schematic illustration of moment distribution in the specimens

lower values. This agrees with the failure modes observed in the experiment. Based on these discussions, it may be concluded that the traditional approach of beam-column joint design based on cruciform specimens is conservative for first-floor joints.

\section{Anchorage bond force versus drift and strains along beam bars}

Based on the measured strains of longitudinal beam bars at the two column faces (Figure 13), the anchorage force can be calculated by Equation 3. The anchorage force is defined as the difference in total forces of steel bars at the two opposite column faces. It represents the transfer of tensile force from the beam steel bars to the surrounding concrete in the joint panel through bond. The anchorage force, computed from the bottom beam bar strain, is plotted against the applied drift ratio for all specimens in Figure 15.

The anchorage bond strength derived from the development length formula of ACI 318 (ACI, 2008) is expressed by Equation 6 and is plotted in Figure 15 for comparison

$$
\boldsymbol{R}_{\mathrm{b}}=\frac{5}{18} \frac{\left(c+K_{\mathrm{tr}}\right)}{\psi_{\mathrm{t}} \psi_{\mathrm{e}} \psi_{\mathrm{s}} \lambda}\left(f_{\mathrm{c}}^{\prime}\right)^{1 / 2} \pi h_{\mathrm{c}}
$$

With respect to the bond behaviour, the ratio of column depth $h_{\mathrm{c}}$ to beam bar diameter $d_{\mathrm{b}}$ is defined in design codes (ACI, 2008) to indicate the anchorage bond performance. The ratio $h_{\mathrm{c}} / d_{\mathrm{b}}$ is equal to 33, 29 and 25 for specimens CJL/JL, CJM/JM and CJS/JS respectively. According to ACI 318 , this ratio is required to be greater than 20 for an $\mathrm{RC}$ building frame in a high seismic zone.
As can be seen in Figure 15, the anchorage bond force calculated from the measured bar strains exceeds the ACI bond strength in all specimens. It is also found that the anchorage bond force did not decrease rapidly although the column shear force showed a marked decrease in the post-peak region (Figure 11), particularly for specimens CJM/JM and CJS/JS. Measured strain along the beam bars is plotted in Figure 13: there is a similar trend between the strain profiles of specimens in both series. In most cases, the strain lines exhibited a certain slope throughout the entire loading cycle. This indicates that the anchorage bond between steel bars and the surrounding concrete was not lost throughout the load range.

For specimens CJM/JM and CJS/JS, the strain in the steel bars at the left-hand column face increased with drift cycle until it reached the peak load. After the peak, the applied force dropped and the strains at the two column faces decreased correspondingly. However, the strain at the right-hand column face also dropped proportionally, resulting in almost no change in the slope of the measured strain lines. The bond force was thus maintained even after the specimen attained peak load and the column shear force was on the descending line.

On the other hand, specimen JL/CJL shows a gradual drop in bond force despite the increase in column shear force after yielding (Figure 15(a)). This decrease in bond force was caused by plastic tensile strain developed in opposite column sections as a result of bar yielding. When the load direction was reversed, the high plastic tensile strain did not return to compressive strain (i.e. residual tensile strain existed). The crack did not close perfectly and the compressive stress on the steel bar was lower. As a result the bond force, which was computed from the difference in bar stress at two opposite column faces, decreased. However, the anchorage bond is not lost as the strain at the middle of the column is still lower than that at column faces.

\section{Strain along steel bars in top and bottom column}

The strain gauge readings from column longitudinal bars at the base and at $50 \mathrm{~mm}$ below the beam are shown in Figure 16 for specimens CJL, CJM and CJS. As can be seen, the strain at the top section is considerably less than that at the bottom section, indicating a larger moment in the bottom section than in the top. Substantial yielding occurred in the bottom column of CJL and CJM while the top of the column in all specimens is far from yielding. As the strain distribution is not symmetrical between the top and bottom parts of the column, the inflection point is located above the mid-height of the column.

The strain profiles indicate the direction of curvature, which also determines the location of inflection point. In specimen CJL, the strain distribution varied in the same direction in both bottom and top sections of the column (Figures 16(a) and 16(d)), indicating bending in single curvature. For specimen CJM, the strain distribution varied in the opposite directions during the initial cycles (i.e. below 1\% drift ratio), indicating double curvature. 
Cyclic performance of beam-column joints with extended column fixed at base. Part I: experimental investigation Joyklad, Pimanmas and Dhakal

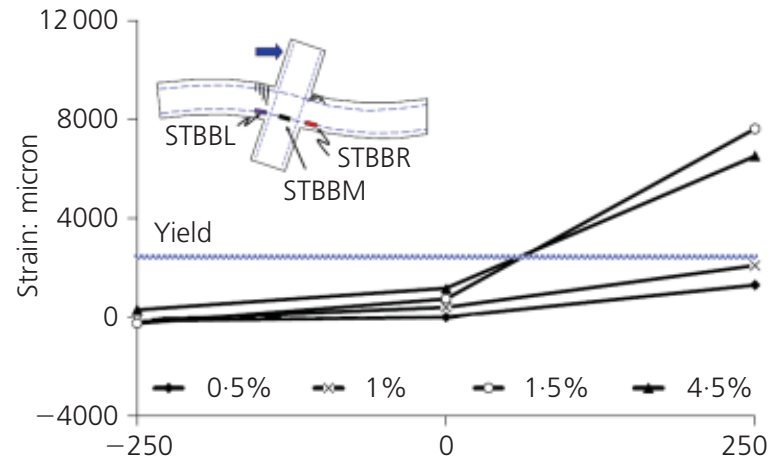

(a) JL

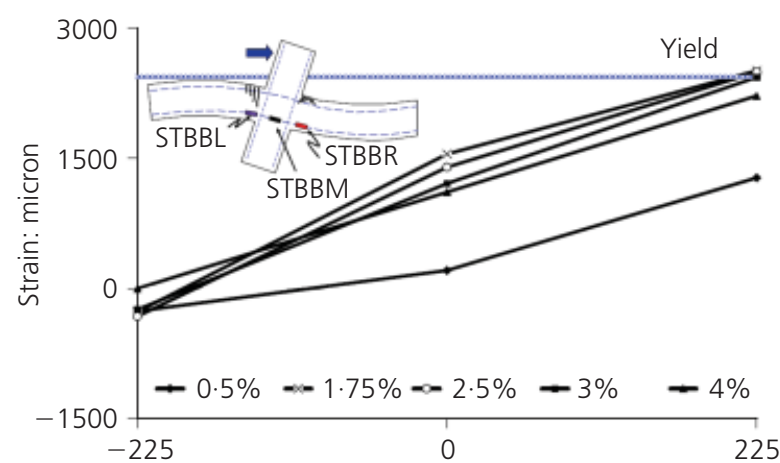

(b) JM

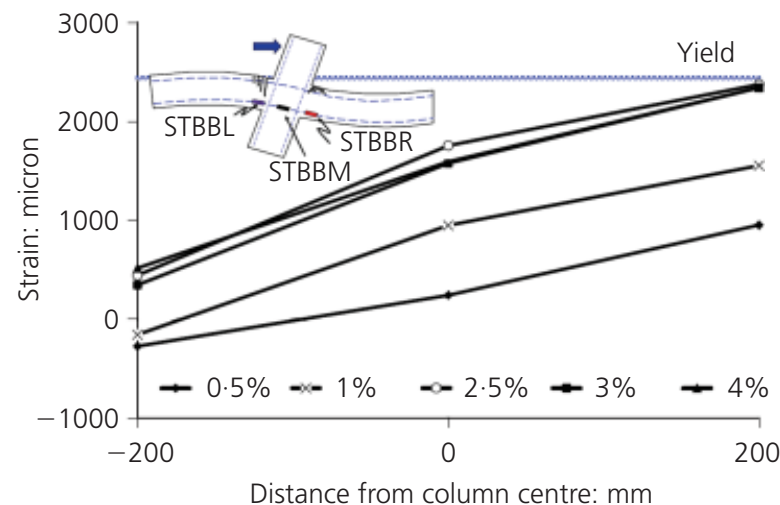

(c) JS

Figure 13. Strain measured along the bottom beam bar at different drift ratios. STBB, strain gauge attached on beam bottom bars at left side of column; STBBM, strain gauge attached on beam bottom bars at middle of column; STBBR, strain gauge attached on beam bottom bars at right side of column

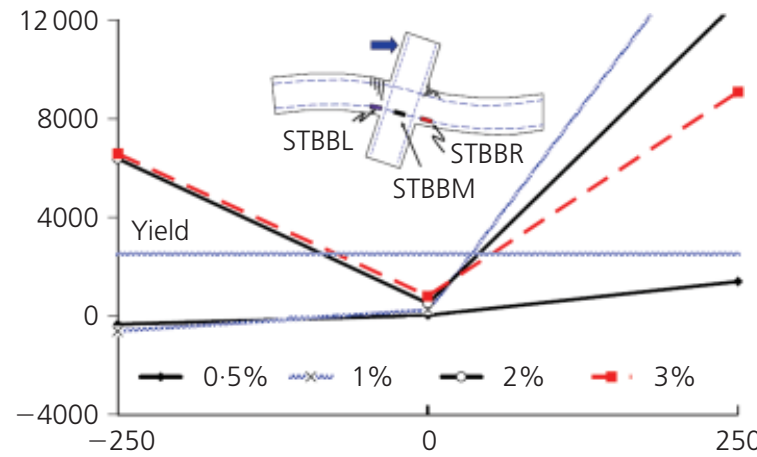

(d) CJL

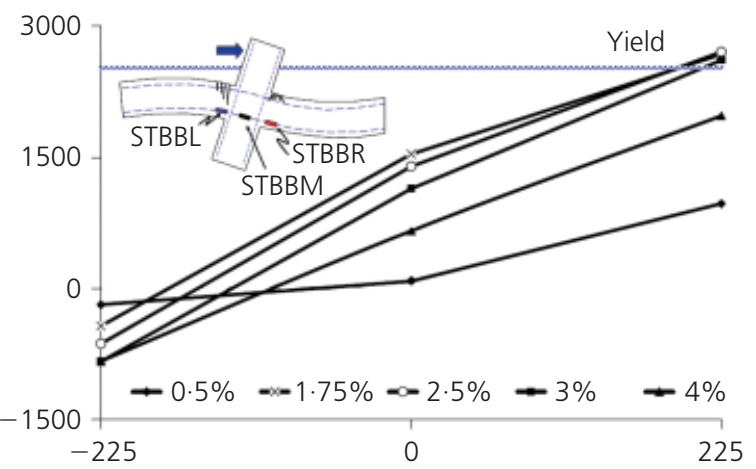

(e) CJM

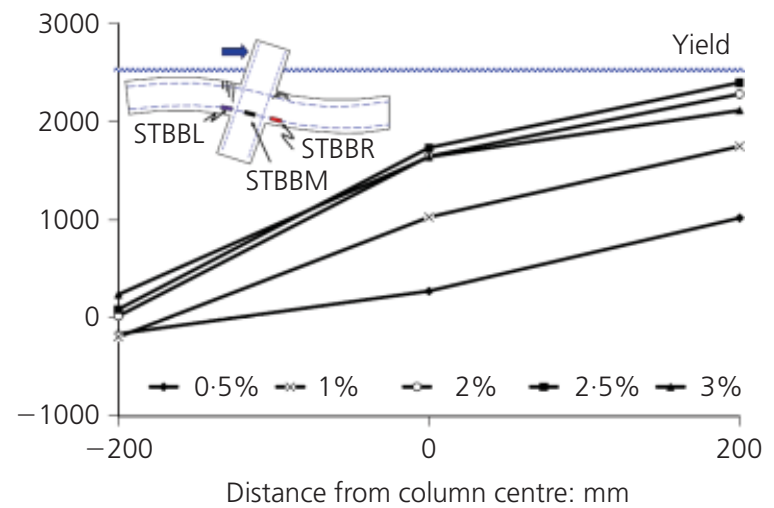

(f) CJS
After $1 \%$ drift, the strain distribution in the top part rapidly changed to the same direction as that in the bottom part, causing the column to be in single-curvature bending (Figures 16(b) and 16(e)). For specimen CJS, the strain distribution varied in opposite directions in the beginning but changed to the same direction after 3\% drift cycle (Figures 16(c) and 16(f)).

\section{Location of inflection point}

To locate the inflection point, the moments at the top and bottom section of the column, which were computed directly from the measured steel strains, are plotted in Figures 17(a) and 17(b); the signs of the moments indicate the direction of bending. As can be seen, the moment plots show a trend similar to the strain profiles. In particular, the moments at the top and bottom part of the column were in the same direction in CJL whereas, for specimens CJM and CJS, the moments were in the opposite direction in the initial drift cycles and then in the same direction after a certain drift value. Based on these moments, the shear span $a$ (i.e. the distance from the fixed base to the inflection point in the column) can be calculated. Figure 18 plots $a / h_{2}$ 


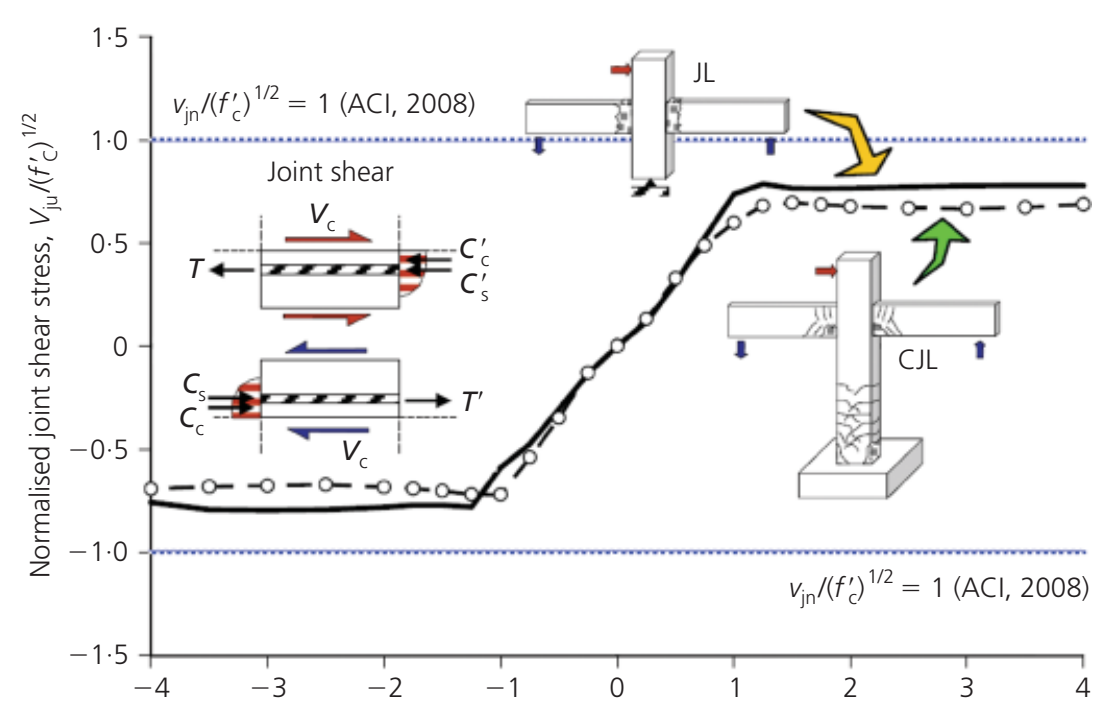

(a) $L$ specimens

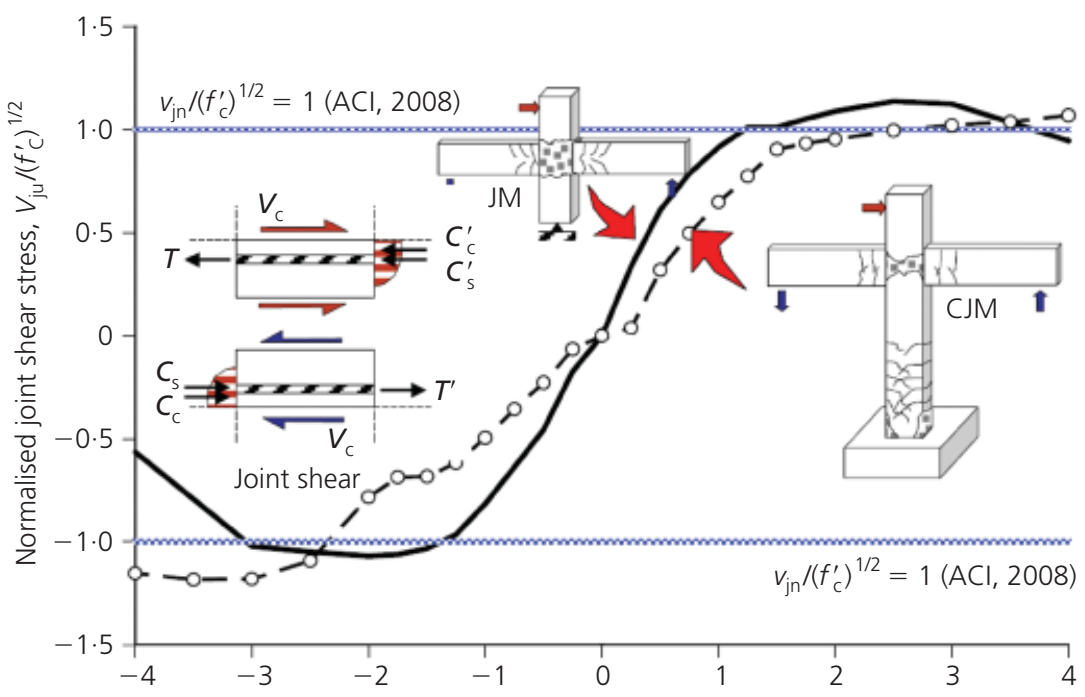

(b) M specimens

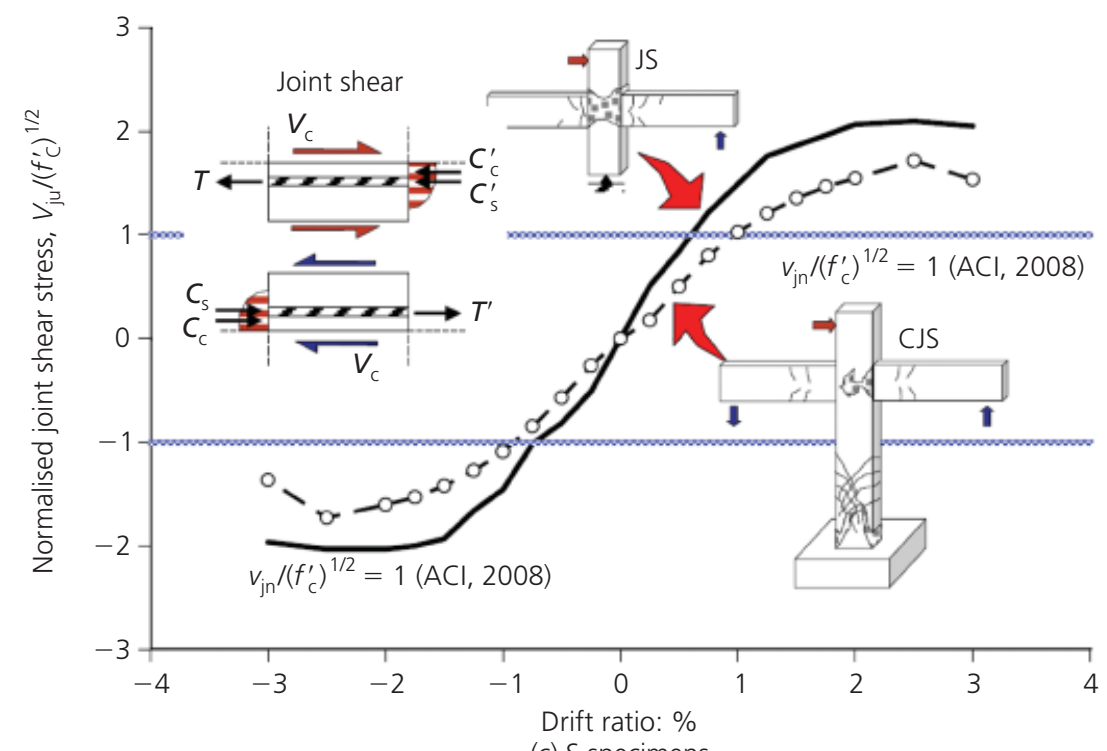

Figure 14. Joint shear force comparison 
Magazine of Concrete Research Volume 64 Issue 9
Cyclic performance of beam-column joints with extended column fixed at base. Part I: experimental investigation Joyklad, Pimanmas and Dhakal

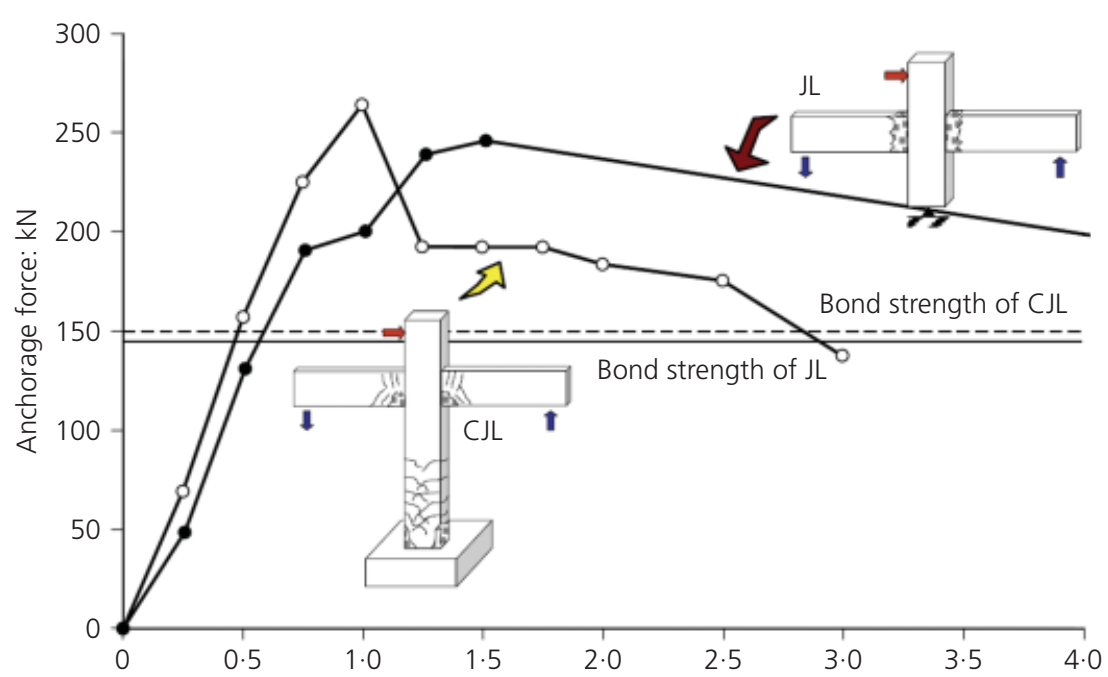

(a) $\mathrm{L}$ specimens

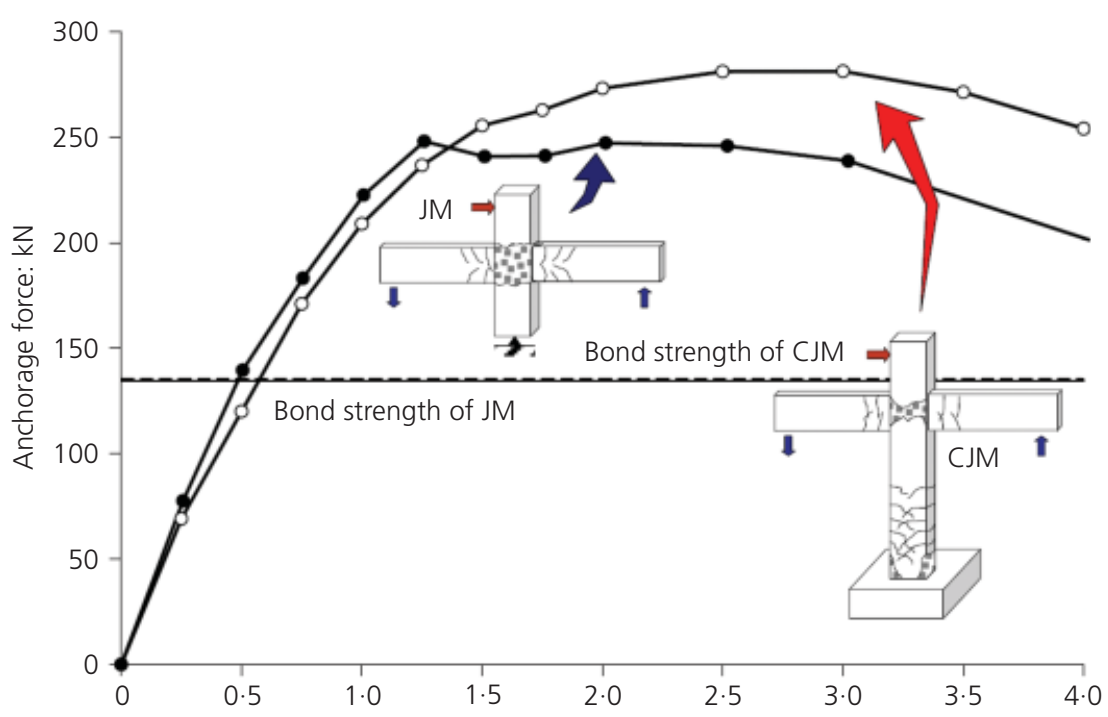

(b) M specimens

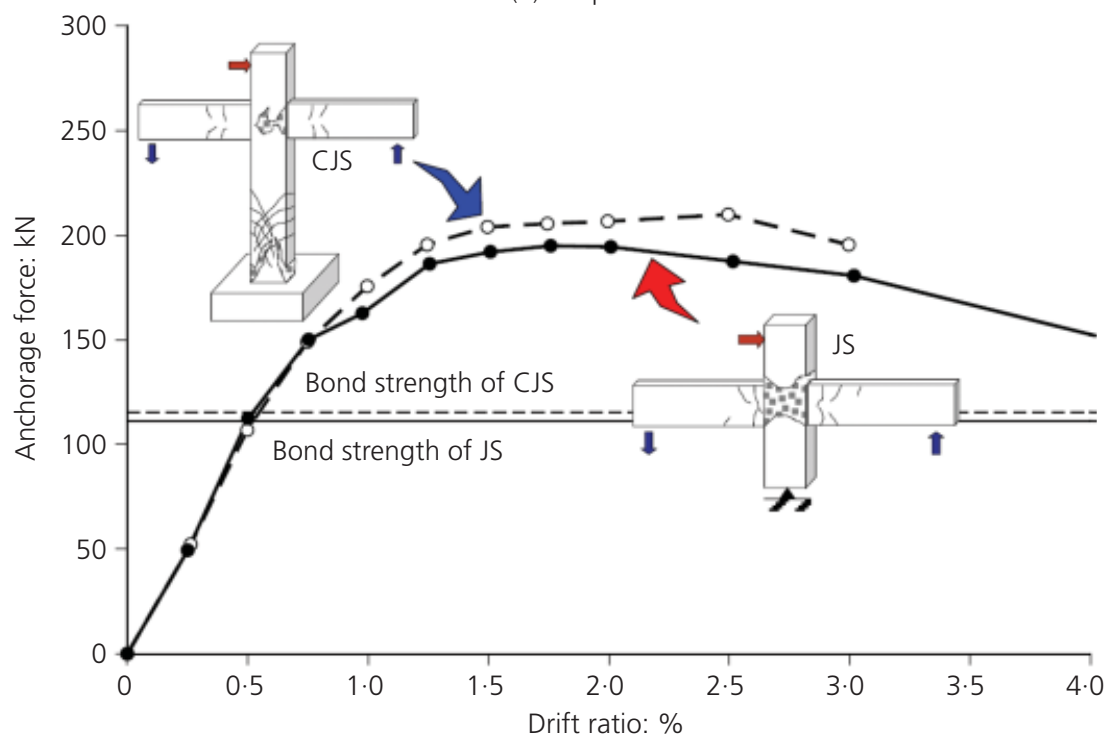

(c) S specimens

Figure 15. Anchorage force in bottom bars 
Cyclic performance of beam-column joints with extended column fixed at base. Part I: experimental investigation Joyklad, Pimanmas and Dhakal

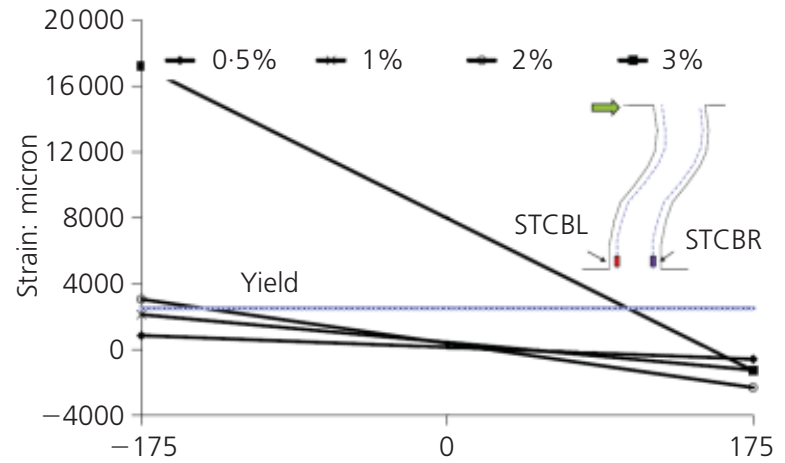

(a) CJL bottom column

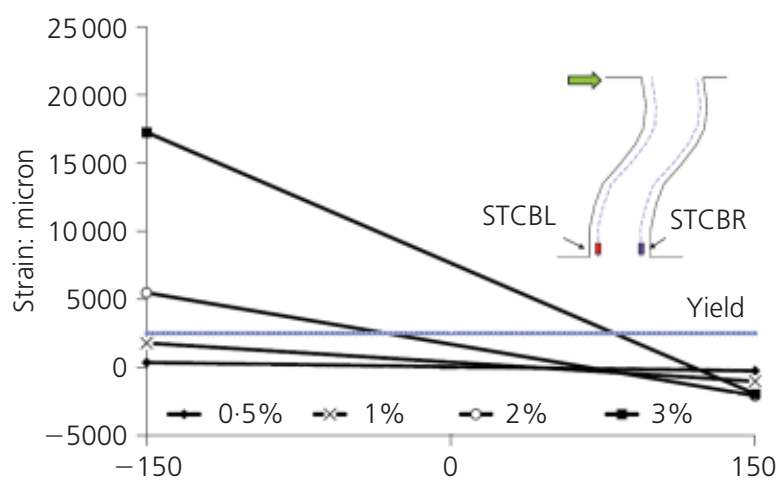

(b) CJM bottom column

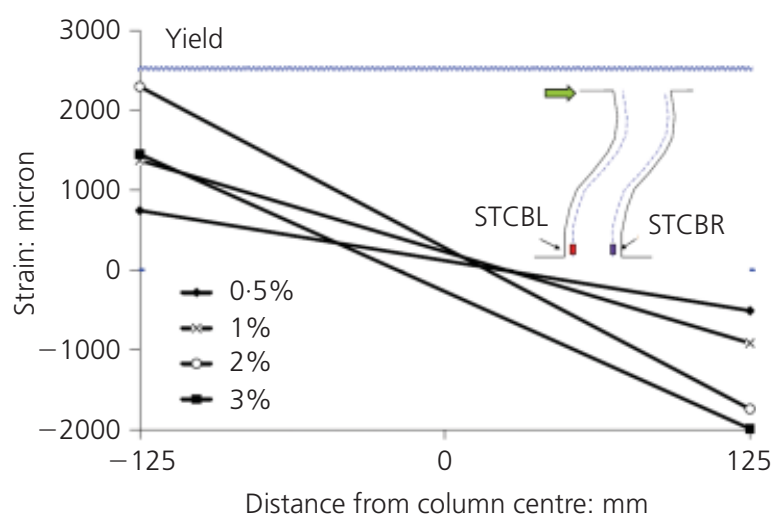

(c) CJS bottom column

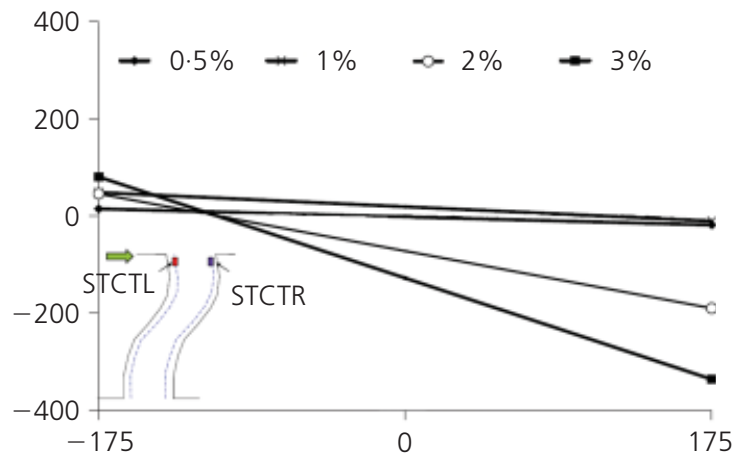

(d) CJL top column

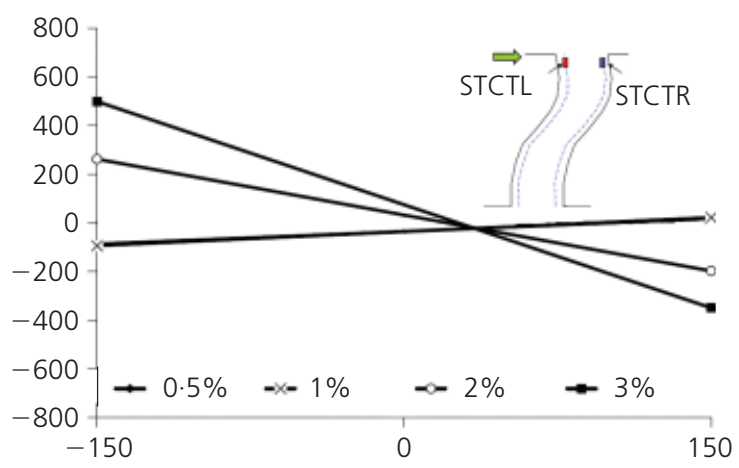

(e) CJM top column

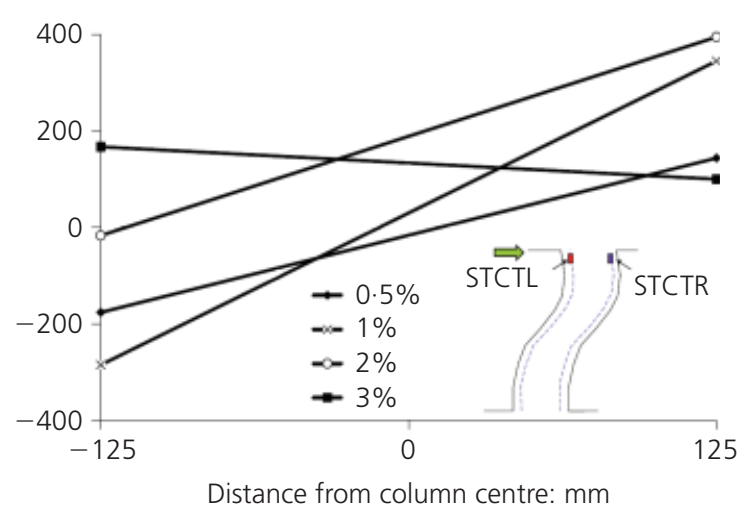

(f) CJS top column

Figure 16. Strain measured in columns of series 2 specimens at different drift ratios. STBC, strain gauge attached on column longitudinal bar at bottom section on the left side; STCBR, strain gauge attached on column longitudinal bars at bottom section on right side; STCTL, strain gauge attached on column longitudinal bar at top section on left side; STCTR, strain gauge attached on column longitudinal bars at bottom section on right side

against applied drift ratio. It can be seen that when the size of column is larger (or when the column has comparatively larger stiffness), such as in the case of CJL, the shear span extends to full column height (i.e. $a / h_{2}=1$ ) and the column is actually in single-curvature bending. The location of the inflection point can be calculated from
7. $a=\frac{\left(h_{1}+h_{2}\right) L I_{\mathrm{c}}+3 h_{2}^{2} I_{\mathrm{b}}}{L I_{\mathrm{c}}+6 h_{2} I_{\mathrm{b}}}$

where $h_{1}$ and $h_{2}$ are the height of top and bottom columns and $I_{\mathrm{c}}$ and $I_{\mathrm{b}}$ are the moment of inertia of the column and 
Cyclic performance of beam-column joints with extended column fixed at base. Part I: experimental investigation Joyklad, Pimanmas and Dhakal

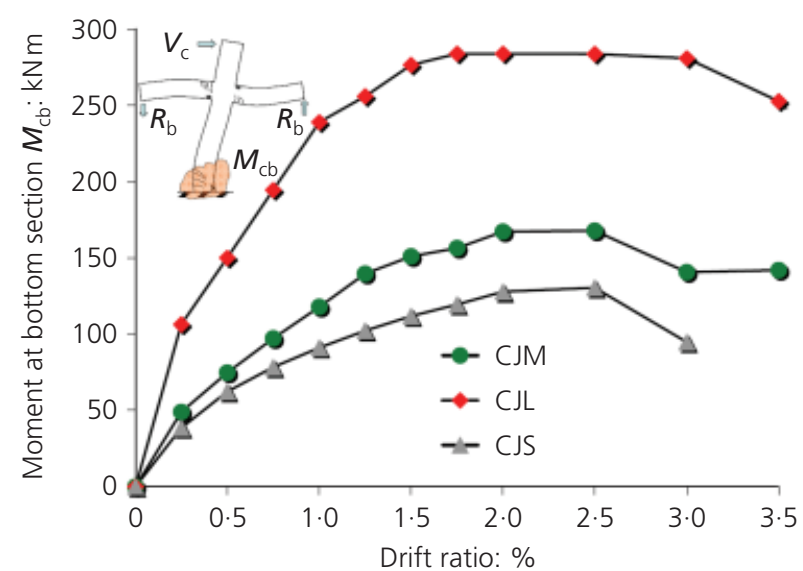

(a)

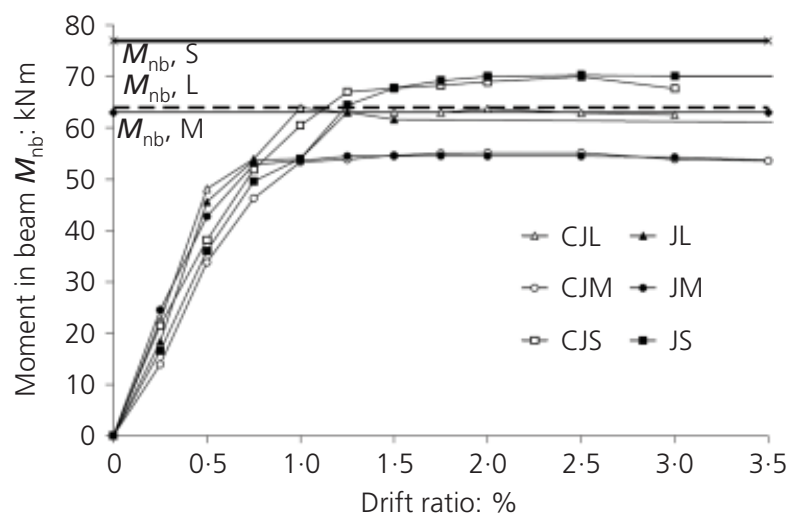

(c)

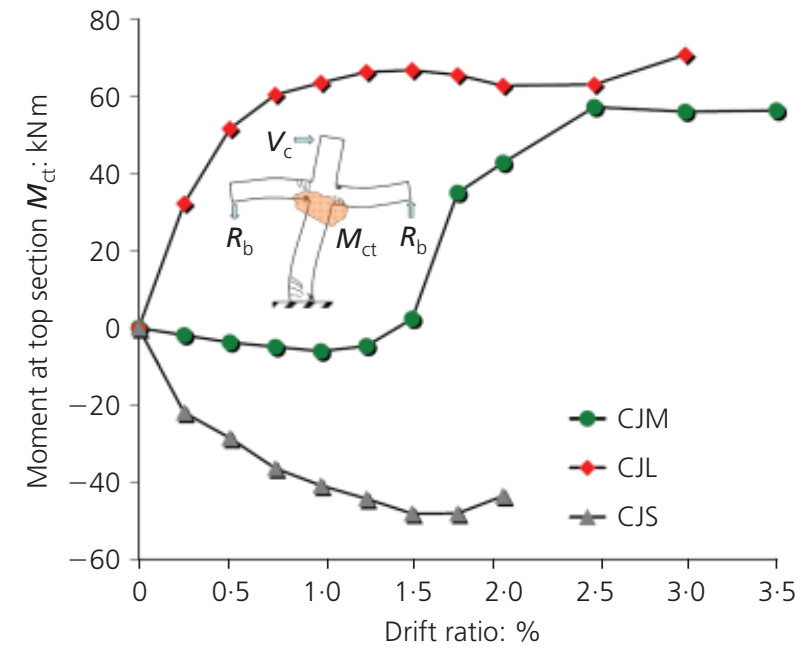

(b)

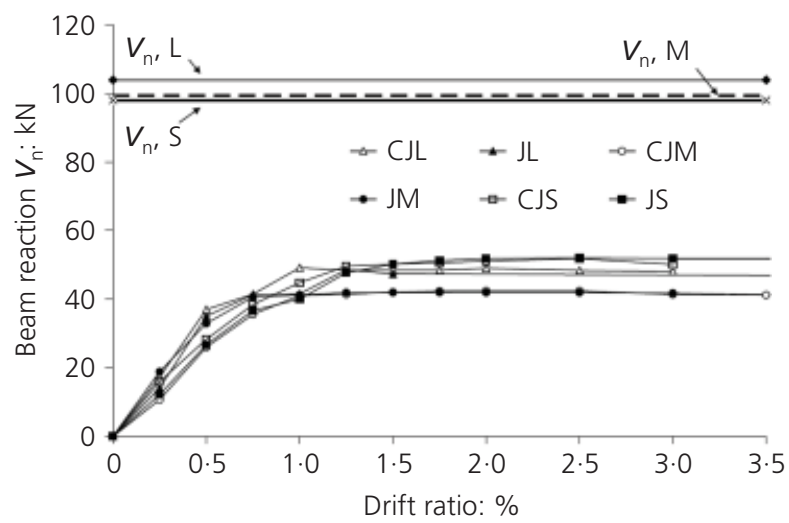

(d)

Figure 17. Moment and shear at critical sections

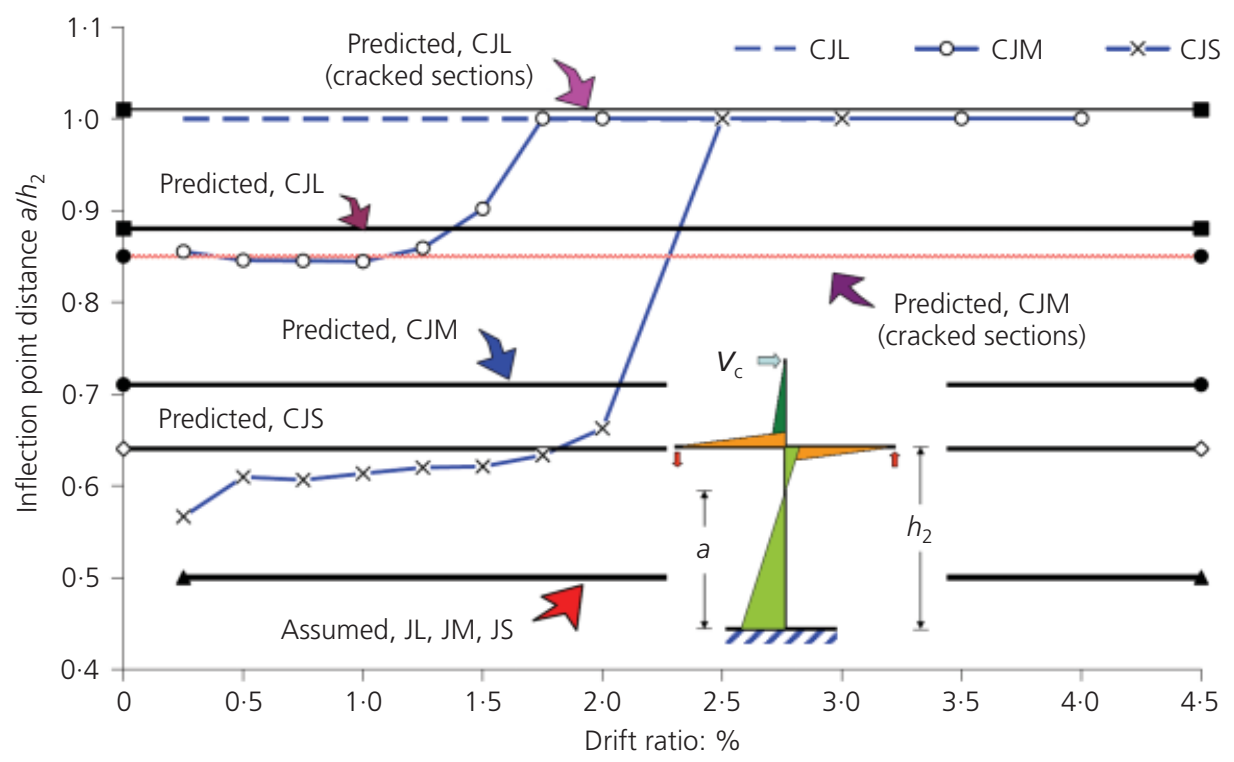

Figure 18. Variation of inflection point in the bottom column with drift ratio 
beam respectively (Figure 12). The beam span $L$ is measured from the centreline of the column to each end, as shown in Figure 12. The inflection point locations calculated by Equation 7 for CJL, CJM and CJS are also shown in Figure 18. The ratio $a / h_{2}$ of specimens CJM and CJS is higher than 0.5 but lower than that of CJL, meaning that the columns are subjected to unsymmetrical double curvature. The line at $a / h_{2}=0.5$ is plotted for specimens in the first series, which assumes that the inflection point is located at the mid-height of the bottom column. The actual inflection point location is higher than the value calculated by Equation 7 because the calculation is based on the gross stiffness of the beam and column. For comparison, the inflection point location was also calculated using a reduced stiffness to represent the cracked condition (i.e. $I_{\mathrm{b}}=0 \cdot 5 I_{\mathrm{gb}}$ ), as shown in Figure 18. Close agreement with measured location can be seen when this reduced stiffness is used.

As Figure 18 suggests, all three specimens turn into single curvature (i.e. $a / h_{2}=1$ ) after the beam yields. For example, specimens CJM and CJS are changed from double curvature to single curvature at $1.75 \%$ and $2.5 \%$ drift respectively. As the inflection point moves up, the force transferred through the joint is decreased, but a higher force is induced in the bottom column. It is also evident that, although the failure may initiate in the beam-column joint as in JM and JS in the initial loading stage, it will gradually move to the bottom part of the column at a later stage. Consequently, the design of columns must pay attention to movement of the inflection point.

\section{Reaction and moment in beam}

The strains measured from the beam bars at the section close to the column faces were converted to beam moments via sectional moment-curvature relations. Using the equilibrium equation (Equation 5), beam shears (i.e. beam reactions) were computed directly from the calculated moments. The beam moment and shear against applied drift ratio are plotted in Figures 17(c) and 17(d), where it can be seen that the calculated beam moment in $\mathrm{CJL} / \mathrm{JL}$ is equal to the nominal moment capacity. This is consistent with the experimental result that indicated flexural failure in the beam after $1 \%$ drift ratio. As expected, the beam moments in the $\mathrm{S}$ and $\mathrm{M}$ specimens are lower than their moment capacities, which also agrees with the experimental results. As all the beams are governed by flexural mode, the calculated beam shear is lower than the shear strength (Figure 17(d)). As a crossverification, the beam reaction and moment at the column base (Figure 17(a)) were used to back-calculate the column shear force; this is plotted against drift ratio in Figure 19, which shows that the measured column shear force agrees well with the backcalculated values. Small differences observed in some cases may be due to the use of the average beam reaction rather than treating the two reactions separately. The discrepancy observed in specimen CJL is probably due to the assumption of a constant yield strain while the bars actually developed a large plastic strain.

\section{Conclusions}

The seismic performance of beam-column sub-assemblages with different inflection point locations was studied experimentally. The following conclusions may be drawn from the test results.

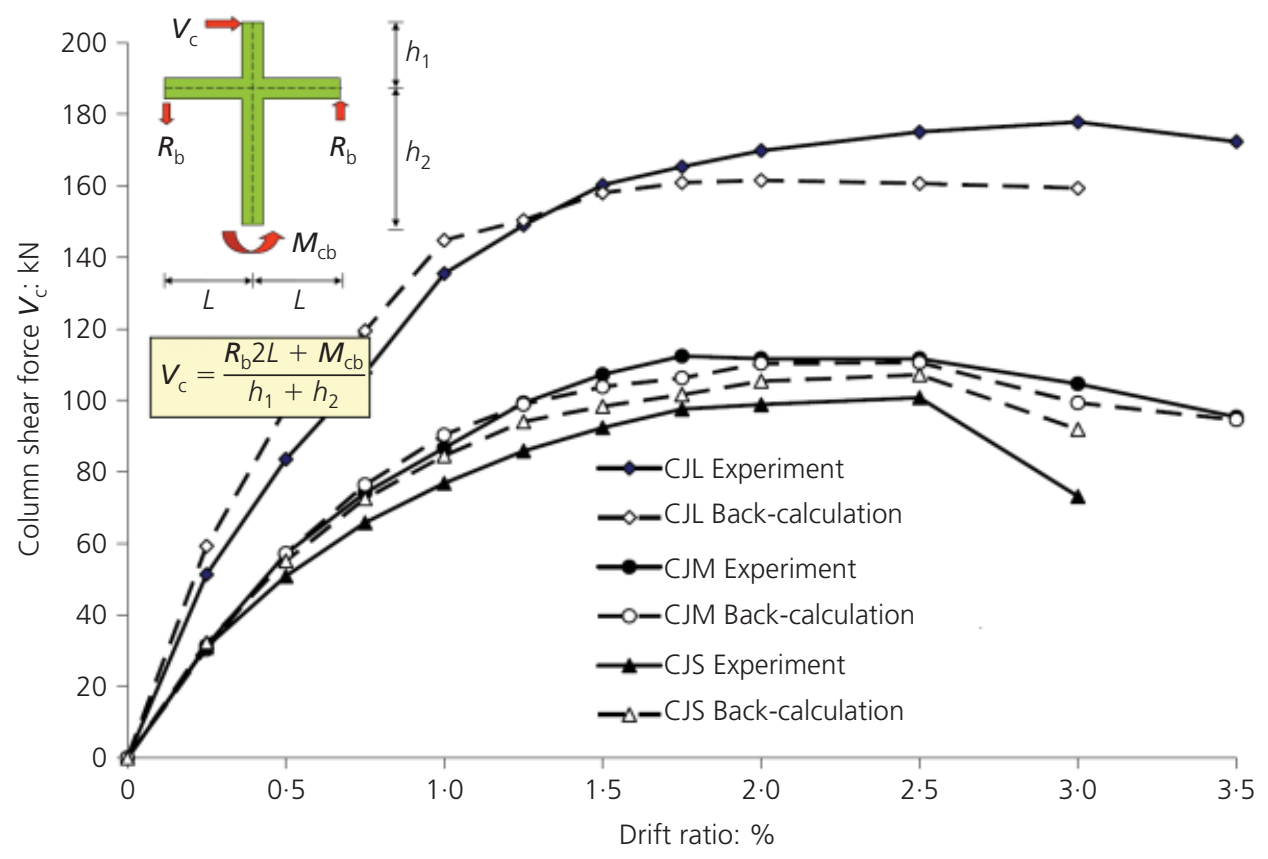

Figure 19. Comparison of column shear forces from experiment and back-calculation 
- There is a significant difference in the behaviour of isolated beam-column joints and beam-column joints with columns extended to the base. The traditional double-cantilever test configuration is not appropriate to represent the first floor of a building frame.

- In the case of an integrated beam-column joint and column specimen, a higher force is transmitted into the column while the horizontal joint shear force is reduced.

- The inflection point in a column at the first storey of a building frame is located between the mid-height and the upper end of the column, depending on relative beam and column stiffness and the yielding condition of the beam.

- When the column has a higher stiffness than the beam, the inflection point tends to be located close to the joint rather than the mid-height of the bottom column. The bottom column is therefore under a cantilever condition.

When the column has a lower stiffness than the beam, the inflection point may be close to the mid-height of the bottom column in the elastic stage. As the beam yields, the inflection point tends to move towards the upper joint.

- The relative stiffness of beam and column has a significant impact on the behaviour of both the beam-column joint and column, especially at the first floor of the frame. The column shear force, joint shear force and failure mode may be correctly predicted if the location of the inflection point is estimated correctly.

\section{Acknowledgements}

The authors are very grateful to the Royal Golden Jubilee PhD programme (RGJ) of the Thailand Research Fund (TRF) and Thammasat University for providing research funds and financially supporting an exchange visit, and to the Asian Institute of Technology for providing test facilities. The first author also thanks the University of Canterbury for providing a study opportunity.

\section{REFERENCES}

ACI (American Concrete Institute) (2008) ACI 318-08: Building code requirements for structural concrete and commentary. ACI, Farmington Hills, MI, USA.

Aycardi LE, Mander JB and Reinhorn AM (1994) Seismic resistance of reinforced concrete frame structures designed only for gravity loads: experimental performance of subassemblages. ACI Structural Journal 91(5): 552-563.

Benavent-Climent A, Cahís X and Vico JM (2010) Interior wide beam-column connections in existing RC frames subjected to lateral earthquake loading. Bulletin of Earthquake Engineering 8(2): 401-402.

Beres A, White RN and Gergely P (1992) Seismic Behavior of Reinforced Concrete Frame Structure with Nonductile Details: Part I - Summary of Experimental Finding of Full Scale Beam-column Joint Test. National Center for Earthquake Engineering Research, Buffalo, NY, USA, Technical report 92-0024.

Bing L and Pan TC (2007) Seismic behavior of non-seismically detailed reinforced concrete structural systems and components - what have we been learning? Journal of Earthquake and Tsunami 1(2): 139-159.

Bing L, Pan TC and Tran CTN (2009) Seismic behavior of nonseismically detailed interior beam-wide column and beam-wall connections. ACI Structural Journal 106(5): 591599.

Burnett EFP and Trenberth RJ (1972) Column load influence on reinforced concrete beam-column connection. ACI Journal 69(2): 101-109.

CEB (Comité Euro-International du Béton) (1996) RC Frames under Earthquake Loading. Thomas Telford, London, UK.

Chiba O, Fukuda T, Toritani T et al. (1992) Experimental and analytical studies on the seismic behavior of reinforced concrete frame-wall structural building. Proceedings of the 10th World Conference on Earthquake Engineering, Madrid, Spain. Balkema, Rotterdam, the Netherlands, 3245-3251.

Dhakal RP, Pan TC, Irawan P et al. (2005) Experimental study on the dynamic response of gravity-designed reinforced concrete connections. Engineering Structures 27(1): 75-87.

Durrani AJ and Wight JK (1985) Behavior of interior beam-tocolumn connections under earthquake-type loading. $A C I$ Journal 82(3): 343-350.

Ghee AB, Priestley MJN and Paulay T (1989) Seismic shear strength of circular reinforced concrete columns. $A C I$ Structural Journal 86(1): 45-59.

Hakuto S, Park R and Tanaka H (2000) Seismic load tests on interior and exterior beam-column joints with substandard reinforcing details. ACI Journal 77(1): 11-25.

Hanson NW and Conner HW (1967) Seismic resistance of reinforced concrete beam-column joints. Journal of the Structural Division, ASCE 93(5): 553-560.

ICC (International Code Council) (2006) International Building Code. Country Club Hills, IL, USA, IBC 2006.

Jirsa JO (1974) Factors influencing the hinging behavior of reinforced concrete members under cyclic overloads. Proceedings of the 5th World Conference on Earthquake Engineering, Rome, Italy. Edigraf, Rome, Italy, vol. 1, pp. 1119-1207.

Kuang JS and Wong HF (2005) Improving ductility of nonseismically designed RC columns. Proceedings of the Institution of Civil Engineers - Structures and Buildings 158(1): $13-20$.

Kunnath SK, Hoffmann G, Reinhorn AM and Mander JB (1995) Gravity load-designed reinforced concrete buildings-Part II: Evaluation of detailing enhancements. ACI Structural Journal 92(4): $1-9$.

Linzhi C, Xilin L, Huanjun J and Jianbo Z (2009) Experimental investigation of damage behavior of RC frame members including non-seismically designed columns. Earthquake Engineering and Engineering Vibration 8(2): 301-311.

Park R (2002) A summary of results of simulated seismic load tests on reinforced concrete beam-column joints, beams and column with substandard reinforcing details. Journal of Earthquake Engineering 6(2): 147-174.

Paulay T, Park R and Priestley MJN (1978) Reinforced concrete 
beam-column joints under seismic actions. ACI Journal

78(11): 585-593.

Pessiki SP, Conley CH, Gergely P and White RN (1990) Seismic Behavior of Lightly Reinforced Concrete Column and Beamcolumn Joint Details. State University of New York at Buffalo, USA, Technical report NCEER-90-0014.

Quintero-Febres CG and Wight JK (2001) Experimental study of reinforced concrete interior wide beam-column connections subjected to lateral loading. ACI Structural Journal 98(4): 572-582.

Ramberg W and Osgood WR (1943) Description of Stress-Strain Curves by Three Parameters. National Advisory Committee for Aeronautics, Washington, DC, USA, Technical note 902.

Saatcioglu M and Ozcebe G (1989) Response of reinforced concrete columns to simulated seismic loading. $A C I$ Structural Journal 86(1): 3-12.

SANZ (Standard Association of New Zealand) (2006) NZS 3101: Design of concrete structures Vols 1 and 2. SANZ, Wellington, New Zealand.

Soleimani D, Popov EP and Bertero VV (1979) Hysteretic behavior of reinforced concrete beam-column subassemblages. ACI Journal 76(11): 1179-1195.
Sugano S and Nagashima T (1985) Structural design and research of reinforced concrete tall buildings. Proceedings of Seminar on Reinforced Concrete High-rise Buildings in Japan with Special Concern on Aseismic Design of Beam-column Joints (Kurose Y and Jirsa JO (eds)). University of Texas at Austin, TX, USA, pp. 85-129.

Supaviriyakit T and Pimanmas A (2008) Comparative performance of sub-standard interior reinforced concrete beam-column connection with various joint reinforcing details. Materials and Structures 41(3): 543-557.

Supaviriyakit T, Pimanmas A and Warnitchai P (2007) Cyclic response of non-seismically detailed interior RC beamcolumn connection with varying column tributary area. Magazine of Concrete Research 59(5): 351-365.

Uzumeri SM (1977) Strength and ductility of cast-in-place beam column joints. Proceedings of a Symposium on Reinforced Concrete Structures in Seismic Zones (Hawkins N (ed.)). American Concrete Institute, Detroit, MI, USA, SP-53, pp. 293-350.

Vintzileou E and Stathatos A (2007) Assessment of the seismic behaviour of RC columns. Engineering Structures 29(7): 1296-1311.

\section{WHAT DO YOU THINK?}

To discuss this paper, please submit up to 500 words to the editor at www.editorialmanager.com/macr by 1 March 2013. Your contribution will be forwarded to the author(s) for a reply and, if considered appropriate by the editorial panel, will be published as a discussion in a future issue of the journal. 